\title{
Self-Generation and Households' Willingness to Pay for Reliable Electricity Service in Nigeria
}

\section{Musiliu O. Oseni*}

August, 2016

\begin{abstract}
Many households in developing countries often engage in self-generation to mitigate the impacts of poor public electricity provision. What is less well known, however, is whether (and how) self-generation influences households' willingness to pay (WTP) for service reliability. Using data collected from a sample of Nigerian households, the results reveal that engagement in self-generation is positively correlated with WTP for reliability. This is despite the fact that self-generation reduces the negative welfare impact of unreliability. Further analyses, however, show that backup households' decisions to pay a higher amount than non-backup households are influenced by the costs of self-generation: an increase of N1 (US\$0.006) in self-generation's fuel cost per-hour is associated with WTP about N5.22 (US\$0.032) more in the monthly bill. However, households' WTP US\$0.15-0.16/kWh of improved reliability is smaller than the marginal costs of reliability from selfgeneration - US\$0.27-0.41/kWh. We conclude by discussing the policy implications of our findings.
\end{abstract}

Keywords: Self-generation, matching method, willingness to pay, contingent valuation, households, Nigeria

* Research Associate, Bartlett Faculty of the Built Environment, University College London, 1-19 Torrington Place, Bloomsbury, London, WC1E 7HB. musloseni@yahoo.com; m.oseni@ucl.ac.uk. 


\section{INTRODUCTION}

Despite the importance of reliable energy services to consumer welfare, access to uninterrupted electricity services remains a critical problem facing households in Nigeria. Currently, the average Nigerian household experiences power outages for around 19 hours daily (National Bureau of Statistics (NBS), 2012). The poor electricity situation in the country is generally attributed to the inadequate financing of generation and distribution capacities due to poor patronage by private investors (Presidential Task Force on Power 2011; Nnaji 2010). ${ }^{1}$ Private investors are reluctant to invest in the power sector because the highly subsidised tariff system currently operating in the country does not guarantee a return on investment.

For most Nigerians, tackling the poor electricity supply means the installation of private backup generators. ${ }^{2,3}$ Recent estimates indicate that approximately one in four Nigerian homes has a gasoline- or dieselpowered generator (National Bureau of Statistics (NBS), 2012). According to the Global Business Research Institute, around US\$450 million was spent on the importation of backup generators in 2011, and this amount is expected to more than double by 2020 (Mgbeokwere 2013). This implies that the amount spent on the importation of diesel-powered generators in 2011 was equivalent to approximately 26 per cent of the sales value of the publicly provided electricity in that year. Although backup generators installed by households could reduce the welfare losses (e.g., reduction in food spoilage) associated with poor reliability, they can also cause serious environmental and health problems due to carbon emissions, and there is evidence of deaths directly linked to the smoke emanating from backup generators in Nigerian homes (Ogundipe 2013). ${ }^{4}$

Finding a permanent solution to the low-quality power supply in Nigeria, as for many other developing countries, would require huge investments in both the grid and off-grid (e.g., solar PV plus storage and wind) generation, and an upgrade of the transmission and distribution facilities. Such investments would, however, require active participation by private investors, especially given the recent decline in government revenue owing to the rapid decrease in oil prices. However, ensuring private investors' active participation in the power sector would require an increase in tariffs and the use of a cost-reflective pricing system that guarantees a return on investment (Newbery 2002). Thus, there is no doubt that the formulation of effective policies to improve

\footnotetext{
${ }^{1}$ Between 1995 and 2013, for instance, less than 700MW of generation capacity was added to the Nigerian electricity grid. See: www.eia.gov.

${ }^{2}$ Although there are other coping strategies often employed by households for lighting, including kerosene lamps, lanterns, and candles, the closest substitute for grid electricity is backup generators. Only backup generators can be used to power household appliances such as televisions and refrigerators.

3 'Backup generation' and 'self-generation' are used interchangeably in this study.

${ }^{4}$ http://www.vanguardngr.com/2013/10/portable-generators-standby-power-standby-death/.
} 
supply security at cost-reflective tariffs would arguably require: 1) outage cost estimations, which are particularly important for comparing costs to benefits when deciding on investments to improve quality of service; and 2) an evaluation of whether or not consumers would be willing to pay, especially given the high rates of backup adoption, which serves as the common close substitute for public provision.

This study estimates the costs of power outages to Nigerian households, and then evaluates the extent to which these costs might affect their WTP. Specifically, the study aims to answer the following questions: Would Nigerian households be willing to pay for improved reliability and, if so, how much? What are the determinants of households' backup generator adoption? Then, conditional on backup generator ownership: What is the household's response to the proposed reliability-bill trade-offs? How much does it cost a household to self-generate electricity, and how does the self-generation cost (i.e., outage cost) relate to their WTP for improved grid service reliability?

The present study is justified for several reasons. First, although a large number of studies have investigated consumers' WTP for energy services in many countries (see Abdullah and Jeanty, 2011; Abdullah and Mariel, 2010; An et al., 2002; Munasinghe, 1980; Nomura and Akai, 2004; Roe and Teisl et al., 2001 for examples), analysis of WTP for electricity services in Nigeria is limited. ${ }^{5}$ Second, previous studies have concentrated mainly on how service attributes and socioeconomic characteristics of consumers affect their WTP; the extent to which the coping strategies (especially self-generation, being the popular close substitute for public provision in the country) might affect WTP has not yet been explored. Third, we collect new and more granular data that allows us to compute how much it costs a household to self-generate electricity and how that cost (outage cost) relates to their WTP for improved reliability. Our study combines the strengths of both the revealed and stated preference methods to estimate the interruption costs for households and their WTP. In addition, we investigate the factors underlying the behaviours of households in their attempts to mitigate outage losses through backup generation. Also, the survey technique enables us to measure the impact of outage costs on WTP. Lastly, we combine both the traditional maximum likelihood estimator (double-bounded model) and matching methods to examine how a household's engagement in self-generation might influence its WTP. We

\footnotetext{
${ }^{5}$ Otegbulu (2011) studied consumers' WTP for improved electricity services in some selected local government areas of Lagos State. Due to poor electricity supply in the country, the study found that $40-80$ per cent of households used generators daily. He also reported that more than 80 per cent of the sampled households were willing to pay more for electricity. However, the study did not examine whether WTP differed between backup and non-backup households. Moreover, the study could not offer a clear and robust estimate of how much people were willing to pay per unit for improvements in supply. Furthermore, the study relied heavily on descriptive analyses and could not provide the details of the factors that might be responsible for variations in consumers' WTP.
} 
find that backup households' engagement in self-generation positively influences WTP for service reliability, despite the fact that backup generation reduces the negative welfare impacts of unreliability.

The paper is organised as follows. The next section provides a brief review of literature on the methodology for valuing reliability. Section 3 describes the data used for the study. The determinants of households' adoption of backup generators are examined in Section 4. Section 5 deals with the analysis of WTP and its relationship with self-generation. In Section 6, we estimate the marginal outage costs and explore the link between self-generation costs and WTP. The last section concludes and discusses the policy implications of our findings.

\section{BRIEF REVIEW OF LITERATURE ON THE METHODOLOGY FOR EVALUATING RELIABILITY}

In principle, there are broadly three different techniques that can be used to estimate the cost of power outages to residential consumers. ${ }^{6}$ The first approach directly asks consumers to state the costs of various types of outages (see for example Wacker and Billinton, 1989). The second is to use a revealed preference approach. This involves studying the actual behaviour of households in terms of action taken to mitigate the effect of power outages. The principle of revealed preference implies that the cost of an outage may be inferred from the actions taken by consumers to mitigate losses induced by unsupplied electricity. For instance, a consumer might invest in backup generation in order to mitigate the effects of power unreliability on their welfare. Such investment is then used to compute the cost of outage to the consumer. This method has been extensively used to estimate the cost of unreliability to business enterprises (see for example Adenikinju, 2003; Beenstock, Goldin, and Haitovsky, 1997; Bental and Ravid, 1982; Caves, Herriges, and Windle, 1992; Matsukawa and Fujii, 1994; Oseni and Pollitt, 2013), but has rarely been explored in the valuation of reliability to households this is probably due to data limitation at household level. The third approach is to directly or indirectly elicit information on consumers' WTP to avoid blackouts by using a stated preference approach (see for example Abdullah and Mariel, 2010; Beenstock, Goldin, and Haitovsky, 1998; Carlsson and Martinsson, 2008; Carson and Groves, 2007; Layton and Moeltner, 2005).

There are clearly strengths and weaknesses of each of these techniques. For example, while the stated preference technique considers all welfare effects by including non-monetary values of power outages on

\footnotetext{
${ }^{6}$ Caves, Herriges, and Windle (1990) and Woo and Pupp (1992) summarize the outage estimation methods commonly used in the outage cost estimation literature.
} 
consumers' utility, ${ }^{7}$ it is often criticised for suffering from a number of behavioural biases including hypothetical bias, sequencing or question order effect, the starting-point bias (anchoring effect) and status quo problem (Hartman, Doane, and Woo, 1991; Tversky and Kahneman, 1974). However, some of these biases can be mitigated through careful survey design and implementation (Blumenschein, Johannesson, Blomquist, Liljas, and O'Conor, 1998; Blumenschein, Johannesson, Yokoyama, and Freeman, 2001; Longo, Hoyos, and Markandya, 2015). One advantage of the revealed preference technique is that it estimates the cost of power reliability or service quality from the actions already taken by consumers; therefore, it is not subject to bias under subjective evaluation. Our study combines the benefits of the stated and the revealed preferences in estimating the costs of reliability to Nigerian households.

\section{DATA}

The data used for this study was obtained through a survey of Nigerian households in 2013. This section discusses in detail the survey procedures, including the scope and size of the sample, questionnaire design, and household selection.

\subsection{Sample Scope and Size}

While it would be of great interest to conduct a national survey, the available resources were inadequate to carry out such an elaborate study. Constrained by resources - human, financial and time - this survey was limited to two states in southwest Nigeria: Lagos and Osun. Lagos was selected due to its economic and ethnic diversity, and because it is the most commercial city in Nigeria, whereas Osun was chosen due to its relatively modest economic characteristics. ${ }^{8}$ In 2010 purchasing power parity (PPP) prices for instance, the per capita income (GDP per capita) for Lagos was US\$3,362.25, whereas Osun State had a per capita income of US $\$ 1,938.44$ - just a little above the national average of US $\$ 1,806.01 .{ }^{9}$ In each of the states, three local government areas (LGAs) were selected from the three existing senatorial districts. These included the IfakoIjaiye, Kosofe and Surulere LGAs in Lagos State and the Ife Central, Iwo and Osogbo LGAs in Osun State.

\footnotetext{
${ }^{7}$ An example of non-monetary value of outage cost is when an individual is prevented from enjoying their leisure time (e.g., watching favourite programs on TV) or from cooking favourite meals during an outage. While these effects are not traded and do not have direct monetary valuation, they do negatively impact consumers' welfare.

${ }^{8}$ Lagos is the former capital city of Nigeria, and, as a result of this status, it has attracted significant economic and commercial activity. Lagos is the second most populous city in Nigeria, according to the 2006 National Census, and has been reported to have the largest electricity consumption in Nigeria.

${ }^{9}$ The calculations of per capita income were based on 2009 population figures due to the inability to access 2010 figures from the state level. The FCT Abuja was not included in the computation of the national GDP per capita average owing to the lack of GDP data.
} 
To determine the optimal sample size of the target population for our study, we followed the method proposed by the United Nations Statistics Division (2005). Available statistics showed that the average household size was 3.9 and 4.0 for Lagos and Osun respectively, while the proportions of the selected LGAs to the total population were 18 per cent and 17 per cent respectively. The non-response rate was set at 25 per cent based on the response rate from Otegbulu's (2011) study. Using the above information, the country's electrification rates of 55 per cent, assuming a 10 per cent margin of error and a 95 per cent confidence interval, yielded the optimal sample sizes of 673 and 703 for Lagos and Osun respectively.

\subsection{Designing the Questionnaire and Pilot Studies}

Prior to the designing of the questionnaire used, a discussion with randomly selected individuals was held in both Lagos and Osun in August 2011. The idea behind this focus group discussion was to gain knowledge of how people felt about the electricity supply situation in their areas, what might interest them in terms of finding a solution to the problem, and the distribution of WTP. Several questions were discussed. The information obtained from the discussion assisted us in designing the questionnaire, as we knew what would be important to include. For instance, the discussion showed that people were less concerned about who supplied electricity - i.e., they did not mind whether electricity was supplied by the government or private companies, as all they cared about was reliability. Also, the focus group discussion revealed some useful information about the distribution of WTP values.

Subsequently, the questionnaire was designed and divided into three sections. The first section focused on consumers' current electricity payments, outage experiences and WTP. For the WTP questions, we used the double-bounded contingent valuation $(\mathrm{CV})$ method where respondents were asked to pay two different monetary values for the proposed reliability, with the second amount being contingent upon their response to the first value. The double-bounded dichotomous choice (DBDC) question format was used because of its advantages, including its robustness to cognitive and strategic biases (Carlsson and Martinsson, 2008), incentive compatibility (Carson and Groves, 2007), efficiency (Hanemann, Loomis, and Kanninen, 1991), and robustness to poor bid designs (Hanemann, Loomis, and Kanninen, 1991; Hanemann and Kanninen, 1998; Scarpa and Bateman, 2000). However, the double-bounded contingent valuation (CV) also suffers from a number of behavioural biases, including hypothetical bias, sequencing or question order effect and starting-point bias (anchoring effect), and protest bias (Anna Alberini, Veronesi, and Cooper, 2005; Herriges and Shogren, 1996; Veronesi, Alberini, and Cooper, 2011). We corrected for the above mentioned biases using the methods 
recommended by Bateman, Burgess, Hutchinson, and Matthews, (2008), Longo, Hoyos, and Markandya (2015)

and Loomis, Brown, Lucero, and Peterson, (1996).

The second part of the questionnaire focused on households' socioeconomic characteristics, and the last section asked about respondents' household appliances. Having designed the questionnaire, two additional pre-survey pilot studies were conducted. Pilot studies play an important role in social science research by providing information for the planning and justification of the actual survey studies; they are often used by practitioners to pre-test a research instrument (Baker 1994). Pilot testing ensures that a research instrument is used properly and the information obtained is consistent. The first pilot study was carried out during the summer of 2012. The pilot study involved 20 randomly selected households -10 in each of the two states. The purpose of this pilot study was to ensure that respondents understood the questions. After the study, those questions that seemed difficult to understand were modified to use more familiar and less technical words. The last pilot study was conducted just two weeks before the actual study. Baker (1994) found that a sample of 10-20 per cent of the sample size for the actual survey was a reasonable number of participants to be enrolled on a pilot study. Thus, our pilot study involved 101 and 105 randomly selected households - representing 15 per cent of the sample sizes - from Lagos and Osun respectively. ${ }^{10}$ The idea was to validate the questionnaire. ${ }^{11}$

\subsection{Household Selection and Survey Administration}

The sampling frame for this study was the 2006 National Population Census. Nigeria is divided into six geopolitical zones, comprising 36 states plus the FCT. The states are, in turn, subdivided into 774 LGAs. For the national census purposes, the Nigeria Population Commission splits the country further into enumeration areas (EAs), each comprising several households. To avoid selection bias, the number of households selected per LGA was proportional to the total number of EAs in the three selected LGAs in each state. ${ }^{12}$ Households were then selected randomly using the systematic selection of 10 households per EA. This involved obtaining the total number of households listed in a particular EA and then calculating a sampling interval (SI) by dividing the total households listed by 10 . The next step was to generate a random start ('s') from the table of random numbers that stood as the first selection. Consecutive groups of households were selected by adding the SI to

\footnotetext{
${ }^{10}$ Given the time limitations, only around 80 per cent of the potential respondents in each state were finally contacted, of which around 70 per cent responded.

${ }^{11}$ The responses were subjected to a preliminary analysis (but not included in the final analysis) in order to get a sense for how the final results would look.

${ }^{12}$ Maps of the EAs used for the last census for the selected areas were obtained from the office of the National Population Commission at subsidised rates. In Lagos especially, we used the maps as guides for updating the number of households in each EA during listing. In Osun, however, the maps were only useful for locating the areas, because the boundaries of each EA could not be properly identified. As such, we adopted the methodology used by the National Population Commission to create our EAs. The familiarity of the research assistants with the terrain made these activities less tedious.
} 
's'. The determination of the sample size at the household level was based on previous studies by the NBS, in which 10 households per EA were adjudged appropriate (NBS, 2012).

To facilitate the administration of the questionnaires, three research assistants were employed. The selection of these assistants was based on their previous survey experience as well as their familiarity with the study areas. The researchers were young graduates who had previously conducted household surveys as part of their undergraduate research projects. In order to improve the quality of the survey, these assistants were trained for two days. After training, they were examined in the field before the start of the actual survey. Finally, the actual survey was conducted from the end of January through to April $2013 .^{13}$ The target respondents were heads of households (or their representatives) who were responsible for the payment of electricity bills. Out of the total 1,376 questionnaires administered, 1,008 were retrieved. Of the total retrieved, only 835 (representing 61 per cent of the sampled households) were analysed due to the lack of quality responses.

\subsection{Survey Results}

Table 1 compares the background information of the households in our sample with the official estimates. Overall, the table shows that the sample estimates correspond with the official estimates, with the exception of marital status and gender, where it appears that we oversampled married and male respondents. This is not surprising, however. The survey targeted household heads (or their representatives), who are responsible for (or familiar with) the payment of electricity bills, whereas the official estimates were based on the population aged 15 years and above. Similarly, household heads are more likely to be men than women. Despite the similarities between the two estimates, however, we were cautious about taking the background information of the respondents as the approximate characteristics for all households in the states.

\footnotetext{
${ }^{13}$ We thank the following people for their support during the course of data collection: Abdulfatai Abdulazeez, Mutiu Azeez, Kazeem Salawu, Abdulfatai Ajide, Rafiu Ogunkemi, Kamilu Bilawu, Mutair Taiwo and Waziri Babalola.
} 


\begin{tabular}{lllll}
\hline & \multicolumn{2}{l}{ Lagos estimates } & \multicolumn{2}{l}{ Osun estimates } \\
\cline { 2 - 5 } Variable & Official & Sample & Official & Sample \\
\hline Male (\%) & 51.6 & 59.6 & 47.4 & 55.7 \\
Female (\%) & 48.4 & 40.4 & 52.6 & 44.3 \\
Age (mean) & $38.9^{\text {a }}$ & 43.7 & $38.9^{\text {a }}$ & 42.3 \\
Average household size & 3.9 & 4.1 & 4.0 & 4.3 \\
Number of occupants living in a house & - & 14.0 & - & 12.6 \\
Number of children (<5 years) per household & - & 2.8 & - & 2.7 \\
Housing type (\%): & & & & 92.8 \\
Shared house/single room (\%) & 81.0 & 68.0 & 91.4 & 7.2 \\
Flat and others & 19.0 & 32.0 & 8.6 & 33.6 \\
Household owning generator (\%) & - & 78.1 & - & 9 \\
Monthly income (\%)* & & & 99.4 & 96.7 \\
N0-N80,000 (US\$0-US\$515.30) & 92.5 & 76.3 & 0.6 & 3.3 \\
Over N80,000 (>US\$515.30) & 7.5 & 23.7 & 46.0 & 78.6 \\
Marital status: married (\%) & 43.0 & 82.0 & $16.6^{\text {a }}$ & 4.7 \\
Prepaid customers (\%) & $16.6^{\text {a }}$ & 17.5 & 82.8 & 86.7 \\
Employed (\%) & 92.4 & 84.0 & & \\
\hline
\end{tabular}

Notes: ${ }^{a}$ National average;

* 2008 estimates (there was an upward salary review in 2011);

Source: National Bureau of Statistics (NBS) $(2009,2010,2012 b)$; Presidential Task Force on Power (2012) and Author's Household Survey (2013).

A comparison of respondents' background characteristics in our sample in the two states suggests that they were not significantly different in terms of some basic characteristics, including gender, age, number of children per household, household size, employment status, and ownership (or non-ownership) of a home business. However, they differed significantly in terms of housing type, income, ${ }^{14}$ number of occupants per house, hours spent at home, ownership of a backup generator, payment method (prepayment or post-payment), assessment of the current supply performance, and experienced service interruptions from the national grid. Respondents from Lagos were more likely to be rich, less likely to live in a shared house or single room, have more people living together in a house, experience fewer interruptions, spend fewer hours at home and are more likely to own a generator.

With regards to the usage of backup generators, households in the two states do not differ significantly. Generators were mainly used for lighting and powering basic appliances, such as televisions, irons, fans or air conditioners, kettles and computers. The use of generators to power refrigerators was very limited, given the capacity of the generators maintained by the households in our sample. No respondents in our sample indicated that they used their generators to run water pumps. This is not surprising considering the small-size nature of

\footnotetext{
${ }^{14}$ In the questionnaires, income was expressed in ranges in order to increase responses and minimise bias, as people often do not like to disclose their exact income.
} 
backup generators held by (many) households, and given the fact that less than 1 per cent of Nigerian households have a water pumping machine (National Bureau of Statistics (NBS) 2012b).

\section{WHAT DETERMINES HOUSEHOLDS' BACKUP GENERATION ADOPTION?}

Despite the poor reliability of power supply in Nigeria, a significant number of households do not engage in self-generation. In this section, we examine the drivers of households' engagement in self-generation. To evaluate the extent to which (un)reliability of power supply and household characteristics affect the decision to generate electricity in-house, we use a binary choice model, which is based on the following stochastic specification,

$$
\operatorname{Pr}\left(G_{i}=1\right)=\Phi\left(\frac{\alpha_{1} \pi_{i}, \alpha_{2} z_{i}}{\sigma}\right)
$$

where $G_{i}$ is the probability that household $i$ invests in a generator, $\Phi$ is the standard normal distribution function, $\pi_{i}$ represents service attributes (outage time - frequency and duration of outages), $z_{i}$ is a vector of controls, including regional and households characteristics, and $\sigma$ is a standard deviation of normally distributed error terms. Equation (1) is estimated using the probit method. The estimated parameters are presented in Table 2. The results reveal that gender differentials, the level of income, the number of household electrical appliances, and the operation of home-based businesses significantly and positively influence a household's ownership of a backup generator. That income significantly influences the decision to own a generator is not surprising, because high-income households should be able to afford the cost of procuring a generator. Also, rich households are more likely to own more electrical appliances that could only be powered during outages by a backup generator. Similarly, those who operate home businesses would be likely to demand backups because of the importance of backup generation to their business operation.

Conversely, households living in shared apartments, those that reside in Osun State, and those that live in more populated houses have a lower probability of owning a generator. The negative relationship between the aforementioned factors and generator ownership might reflect affordability constraints. For instance, households sharing apartments are more likely to be poor compared to households who do not reside in shared accommodation. Similarly, Osun State's economy is relatively less developed than Lagos's, which might explain the reason for the low probability of generator ownership among Osun residents. Respondents' age is negatively related to the probability of a household engaging in self-generation. Given decades of poor electricity supply in Nigeria, older people were more likely to grow up without electricity, and may have adapted to unreliability and found it "more normal" to live without electricity. 
Table 2: Determinants of Households' Adoption of Backup Generator

\begin{tabular}{|c|c|c|c|}
\hline $\begin{array}{l}\text { Dependent variable: household backup } \\
\text { ownership }\end{array}$ & Coefficient & $\begin{array}{l}\text { Robust } \\
\text { std. error }\end{array}$ & $\begin{array}{l}\text { Marginal } \\
\text { effect }\end{array}$ \\
\hline Male & $0.30 * *$ & $(0.12)$ & 0.12 \\
\hline Income & $0.17 * * *$ & $(0.04)$ & 0.07 \\
\hline Outage time per week (hrs) & -0.0001 & $(0.002)$ & -0.00004 \\
\hline Number of household appliances & $0.11 * *$ & $(0.05)$ & 0.04 \\
\hline Prepayment (dummy) & 0.26 & $(0.19)$ & 0.10 \\
\hline Shared house/single room (dummy) & $-0.41 * *$ & $(0.16)$ & -0.15 \\
\hline Number of occupants & $-0.01 * *$ & $(0.006)$ & -0.01 \\
\hline $\begin{array}{l}\text { Economically active (employed }=1,0 \\
\text { otherwise) }\end{array}$ & 0.28 & $(0.18)$ & 0.11 \\
\hline State dummy (Osun=1, 0 otherwise) & $-0.93 * * *$ & $(0.13)$ & -0.35 \\
\hline $\begin{array}{l}\text { Confident about future improvements (having } \\
\text { confidence }=1,0 \text { otherwise) }\end{array}$ & -0.04 & $(0.11)$ & -0.02 \\
\hline Home business ownership (dummy) & $0.31 * *$ & $(0.12)$ & 0.12 \\
\hline Average hours spent at home per day & 0.01 & $(0.01)$ & 0.002 \\
\hline Age (years) & $-0.02 * * *$ & $(0.004)$ & -0.01 \\
\hline Constant & 0.38 & $(0.44)$ & \\
\hline Number of observations & 679 & & \\
\hline Wald $\chi^{2}$ & 236.24 & & \\
\hline$p>\chi^{2}$ & 0.000 & & \\
\hline
\end{tabular}

Notes: $*$ Significant at the $10 \%$ level; ** significant at the $5 \%$ level; significant at the $1 \%$ level.

The next section investigates the extent to which a household's engagement in self-generation might affect their WTP.

\section{BACKUP GENERATION AND WTP}

\subsection{Double-Bounded Choice or Interval Data Model}

We use the DBDC model to estimate the determinants of households' WTP and how (and the extent to which) households' engagement in self-generation might affect their WTP. A double-bounded model retains the incentive properties of discrete choice and is also more efficient (M. Hanemann, Loomis, and Kanninen 1991). A further advantage of the double-bounded model is that it is fairly robust with respect to poor bid designs resulting from initial parameter misspecification (M. Hanemann et al., 1991; Scarpa and Bateman, 2000). In effect, the higher second bid provides insurance against too low a choice for the initial bid, and the lower second bid provides insurance against too high a choice for the initial bid (M. W. Hanemann and Kanninen, 1998).

In the survey, respondents were offered two rounds of questions, with the second being contingent upon the responses to the first. If the response to the first bid $\left(B_{i}\right)$ is no (or yes), the follow-up question used a 
lower, $B_{i}^{l}$, (or a higher, $B_{i}^{h}$ ) bid value. Then, each respondent would be in one of the following categories: 'yesyes', 'no-no', 'yes-no', or 'no-yes'. Assuming a linear WTP function of the form $W T P_{j}\left(z_{j}, \varepsilon_{j}\right)=\alpha z_{j}+\varepsilon_{j}$, where $z_{j}$ is a vector of individual household characteristics (e.g., backup ownership status, income or appliances) and service attributes, $\alpha$ is a vector of parameter, and $\varepsilon_{i j}$ is the individual (household) unobserved characteristics, which satisfies $\varepsilon_{j} \sim N\left(0, \sigma^{2}\right)$. Under the assumption of a utility-maximising respondent, the loglikelihood function for the above response categories is: ${ }^{15}$

$$
\begin{aligned}
\ln L^{D B}(\varnothing)=\sum_{i}^{N} & \left\{I_{i}^{y n} \ln \left(\Phi\left(z_{j} \frac{\alpha}{\sigma}-\frac{t^{1}}{\sigma}\right)-\Phi\left(z_{j} \frac{\alpha}{\sigma}-\frac{t^{2}}{\sigma}\right)\right)+I_{i}^{y y} \ln \left(\Phi\left(z_{j} \frac{\alpha}{\sigma}-\frac{t^{2}}{\sigma}\right)\right)\right. \\
& \left.+I_{i}^{n y} \ln \left(\Phi\left(z_{j} \frac{\alpha}{\sigma}-\frac{t^{2}}{\sigma}\right)-\Phi\left(z_{j} \frac{\alpha}{\sigma}-\frac{t^{1}}{\sigma}\right)\right)+I_{i}^{n n} \ln \left(1-\Phi\left(z_{j} \frac{\alpha}{\sigma}-\frac{t^{2}}{\sigma}\right)\right)\right\}
\end{aligned}
$$

Here, $t^{1}$ and $t^{2}$ are the first and second bid amounts respectively. $I_{i}^{X X}$ indicates the response category for each respondent: $i, n={ }^{\prime} n o^{\prime}, y={ }^{\prime} y e s^{\prime}$. The maximum likelihood estimator for the double-bounded model, $\emptyset^{D B}$, is the solution to the equation $\partial \ln L^{D B}\left(\widehat{\emptyset}^{D B}\right) / \partial \emptyset=0$. Using the doubleb STATA command developed by Lopez-Feldman (2012), we can directly obtain $\hat{\alpha}$ and $\hat{\sigma}$. Thus, the expected mean WTP from Equation (2) is $E(W T P \mid \alpha, \bar{z})=\hat{\alpha}^{\prime} \bar{z}$.

Table 3 shows the results from the estimation of Equation (2) of the relationship between households' engagements in self-generation, service attributes, households' background characteristics and WTP amount in local currency (naira). Selected households' socioeconomic characteristics included in the regressions were informed by the previous studies. Among the socioeconomic factors that have been found to play significant roles in WTP for electricity services are income, age, gender, and housing type (Carlsson and Martinsson 2007; Abdullah and Jeanty 2011; Abdullah and Mariel 2010), household size, years of residence in the area, employment status, and bank account ownership (Abdullah and Jeanty, 2011), billing accuracy, home-business ownership, level of education of the head of household, and having more school-going children (Gunatilake, Maddipati and Patail, 2012; Gunatilake, Patail and Yang, 2012). Service attributes include the frequency and/or duration of outages (Carlsson and Martinsson 2007; Abdullah and Mariel 2010; Carlsson and Martinsson 2008).

We estimate four models in total: the first two models include a dummy variable, indicating whether a household engages in self-generation, but differ on how service attributes are treated. The first model includes the number of weekly outages and the duration of outages separately, while the second model combines the two

\footnotetext{
${ }^{15}$ See Haab and McConnell (2002) for details.
} 
attributes and treats them as outage time. Instead of a self-generation dummy, the third and the fourth models include self-generation fuel cost per hour (fuel costs) to capture the effect of backup generation on WTP. To test whether the ownership of household electrical appliances influenced WTP, the number of electrical appliances owned by a household is included in the models. ${ }^{16}$

The estimated results show that, with all else being equal, households do not separate the impact of outage frequency and duration when making WTP decisions (Table 3). ${ }^{17}$ Rather, households are more concerned about the total length of outages (outage time) that they suffered. ${ }^{18}$ Thus, we subsequently focus our discussion on the estimates from the models, including outage time (i.e., Models 2 and 4). ${ }^{19}$ In general, consumers who own generators experience longer blackout times, pay for their electricity upfront (prepaid), are economically active, are confident about future service improvements, and are willing to pay more to enjoy a better service. More importantly, both the generator ownership dummy and the per-hour fuel cost of self-generation are significantly related to WTP for service reliability (at 5 per cent and 1 per cent significant level), suggesting that self-generation positively influences WTP.

Conversely, households living in a single room or shared house, and those who spent long hours at home, were less willing to pay for service improvements. We also found that households in Osun State were less willing to pay compared to their counterparts in Lagos. Surprisingly, however, the number of electrical appliances held by households does not significantly influence their WTP for reliability. This might be because most of their appliances are small and are already being run on a generator. This perception is further reinforced by a significant correlation between backup ownership and the number of electrical appliances held by a household (see Table 2). In terms of the absolute size of the effects, the coefficient on backup generator ownership indicates that engagement in backup generation significantly increased WTP extra on top of the monthly bill by N220.13 (US\$1.42). Similarly, an additional N1 (US\$0.006) increase in self-generation's fuel cost per hour is associated with a WTP N5.22 (US\$0.034) on top of the monthly electricity bill.

\footnotetext{
${ }^{16}$ We also test for the effect of household energy appliances by re-estimating our model to include monthly energy consumption instead of the number of appliances. The results do not vary significantly; the coefficient of energy consumption is not significant, while the coefficients of other variables are consistent with the earlier estimates in terms of both magnitude and significance levels.

${ }^{17}$ We run another set of regressions that controlled for community effects by including community (i.e., sampling area) dummies. The results did not show significant differences in the coefficients of most of the key variables. However, most of the coefficients on the community dummies were not significant enough to warrant reportage. Moreover, log-likelihood ratio tests indicate that the models that controlled for state-level effects are better than the models that controlled for community-level effects. Therefore, we stick to the models that control for regional differences through state dummies.

${ }^{18}$ Frequency and duration of outages do not significantly influence WTP individually, but have a joint effect when they are considered in terms of the total outage time. We excluded the variable for education level, as it did not improve the performance of the models. Instead, it distorted the models' performance significantly. Also, the interaction of some variables, such as income with generator ownership, homebusiness ownership with generator ownership, appliances with generator ownership, and hours spent at home with generator ownership did not improve the results. Both the coefficient of the treatment variable and those of the interactions were insignificant.

${ }^{19}$ Although the log-likelihood ratio test suggests no significant difference between the two models, Model 2 is judged to be better, considering the significance of the variables.
} 
For robustness purposes, Table B1 in Appendix B provides sets of regression results where we delete one control variable at a time, in order to be more confident that the results (e.g., the effects of self-generation on WTP) are not driven by unobservables related to our control variables. We see that the results are statistically significant in all cases and the magnitudes of the coefficient estimates are relatively stable.

Table 3: Determinants of WTP for Improved Reliability

\begin{tabular}{|c|c|c|c|c|}
\hline \multirow[b]{2}{*}{ Dependent variable: WTP (Naira) } & \multicolumn{2}{|c|}{ Double-bound } & \multicolumn{2}{|c|}{ Double-bound } \\
\hline & Model1 & Model 2 & Model 3 & Model 4 \\
\hline Male & $\begin{array}{l}37.17 \\
(98.68)\end{array}$ & $\begin{array}{l}38.22 \\
(98.44)\end{array}$ & $\begin{array}{l}26.72 \\
(97.84)\end{array}$ & $\begin{array}{l}28.53 \\
(97.58)\end{array}$ \\
\hline Generator Ownership (dummy) & $\begin{array}{l}211.90 * * \\
(107.21)\end{array}$ & $\begin{array}{l}220.13 * * \\
(106.78)\end{array}$ & & \\
\hline Fuel cost per hours & & & $\begin{array}{l}5.18 * * * \\
(1.41)\end{array}$ & $\begin{array}{l}5.22 * * * \\
(1.39)\end{array}$ \\
\hline Income & $\begin{array}{l}-7.02 \\
(33.88)\end{array}$ & $\begin{array}{l}-2.44 \\
(33.80)\end{array}$ & $\begin{array}{l}-23.05 \\
(34.08)\end{array}$ & $\begin{array}{l}-18.76 \\
(34.00)\end{array}$ \\
\hline Frequency of outages & $\begin{array}{l}6.52 \\
(5.24)\end{array}$ & & $\begin{array}{l}5.86 \\
(5.22)\end{array}$ & \\
\hline Duration of outage (hrs) & $\begin{array}{l}10.40 \\
(17.42)\end{array}$ & & $\begin{array}{l}9.56 \\
(17.31)\end{array}$ & \\
\hline Outage time per week & & $\begin{array}{l}3.30 * * \\
(1.27)\end{array}$ & & $\begin{array}{l}3.24 * * \\
(1.27)\end{array}$ \\
\hline Number of household appliances & $\begin{array}{l}16.70 \\
(38.17)\end{array}$ & $\begin{array}{l}18.09 \\
(37.89)\end{array}$ & $\begin{array}{l}14.24 \\
(37.80)\end{array}$ & $\begin{array}{l}16.37 \\
(37.53)\end{array}$ \\
\hline Prepayment (dummy) & $\begin{array}{l}417.76^{* *} \\
(149.52)\end{array}$ & $\begin{array}{l}418.46^{* * *} \\
(147.11)\end{array}$ & $\begin{array}{l}430.24 * * * \\
(148.49)\end{array}$ & $\begin{array}{l}428.23 * * * \\
(146.07)\end{array}$ \\
\hline Shared house/single room (dummy) & $\begin{array}{l}-333.60 * * \\
(130.91)\end{array}$ & $\begin{array}{l}-308.04 * * \\
(130.82)\end{array}$ & $\begin{array}{l}-312.65^{* *} \\
(130.07)\end{array}$ & $\begin{array}{l}-287.49 * * \\
(129.91)\end{array}$ \\
\hline Number of occupants & $\begin{array}{l}5.79 \\
(5.17)\end{array}$ & $\begin{array}{l}5.42 \\
(5.16)\end{array}$ & $\begin{array}{l}6.19 \\
(5.13)\end{array}$ & $\begin{array}{l}5.81 \\
(5.12)\end{array}$ \\
\hline $\begin{array}{l}\text { Economically active (employed }=1,0 \\
\text { otherwise) }\end{array}$ & $\begin{array}{l}271.17 \\
(146.13)\end{array}$ & $\begin{array}{l}255.73 * \\
(145.57)\end{array}$ & $\begin{array}{l}250.55^{*} \\
(145.21)\end{array}$ & $\begin{array}{l}235.31 \\
(144.61)\end{array}$ \\
\hline State dummy (Osun $=1,0$ otherwise) & $\begin{array}{l}-195.72 * \\
(114.68)\end{array}$ & $\begin{array}{l}-204.12 * \\
(113.32)\end{array}$ & $\begin{array}{l}-182.16 \\
(110.84)\end{array}$ & $\begin{array}{l}-194.24 * \\
(109.50)\end{array}$ \\
\hline $\begin{array}{l}\text { Confident about future improvements } \\
\text { (having confidence }=1,0 \text { otherwise) }\end{array}$ & $\begin{array}{l}321.25 * * * \\
(93.97)\end{array}$ & $\begin{array}{l}366.03 * * * \\
(93.15)\end{array}$ & $\begin{array}{l}325.67 * * * \\
(93.43)\end{array}$ & $\begin{array}{l}370.41 * * * \\
(92.61)\end{array}$ \\
\hline Home business ownership (dummy) & $\begin{array}{l}39.64 \\
(97.62)\end{array}$ & $\begin{array}{l}46.23 \\
(97.25)\end{array}$ & $\begin{array}{l}33.62 \\
(96.81)\end{array}$ & $\begin{array}{l}40.05 \\
(96.45)\end{array}$ \\
\hline Average hours spent at home per day & $\begin{array}{l}-18.29 * \\
(10.67)\end{array}$ & $\begin{array}{l}-17.82 * \\
(10.64)\end{array}$ & $\begin{array}{l}-18.70 * \\
(10.61)\end{array}$ & $\begin{array}{l}-18.32 * \\
(10.58)\end{array}$ \\
\hline Age (years) & $\begin{array}{l}-0.16 \\
(3.23)\end{array}$ & $\begin{array}{l}-0.37 \\
(3.22)\end{array}$ & $\begin{array}{l}-0.31 \\
(3.17)\end{array}$ & $\begin{array}{l}-0.54 \\
(3.16)\end{array}$ \\
\hline Constant & $\begin{array}{l}779.67 * * \\
(387.58)\end{array}$ & $\begin{array}{l}677.88^{*} \\
(367.63)\end{array}$ & $\begin{array}{l}831.88 * * \\
(380.96)\end{array}$ & $\begin{array}{l}723.04 * * \\
(359.38)\end{array}$ \\
\hline Log-likelihood $=$ & -315.29 & -315.22 & -874.82 & -872.15 \\
\hline
\end{tabular}


Table 4 presents the estimates of the mean WTP based on the results from Table 3. On average, consumers were willing to pay between N956.60 (US\$6.16) and N1,160.72 (US\$7.48) on top of their monthly bill to reduce the incidence of power outages to half of its present level. Given the weekly outage time of about 72 hours, which translates to a monthly average of 288 hours, the average household was willing to pay an additional N7.35 (US\$0.05) per one-hour reduction in outage time. This translates to a WTP N10.36 (US\$0.07) on top of the current tariff to enjoy an extra $\mathrm{kWh} .{ }^{20}$ This means that the average Nigerian household would be willing to pay $\mathrm{N} 23.37$ (US\$0.15) per $\mathrm{kWh}$ of additional reliability. ${ }^{21}$ As evidenced in Table 4, and similar to Table 3, the mean WTP estimate suggests that, on average, backup households would be willing to pay around N220.13 (US\$1.42) more than non-backup households. ${ }^{22}$ In other words, a backup household would be willing to pay around 23.6 per cent more than the WTP amount per kWh of a non-backup household, and around 20.8 per cent more than the WTP of an average respondent in our sample. With a typical average monthly bill of N5,038.05 (US\$32.45), this means that engagement in backup generation alone accounts for a WTP an additional 4.4 per cent of the current electricity bill monthly. These findings illustrate that, despite people's willingness to enjoy a better electricity service, the differences between backup and non-backup households are significant. We re-examine the robustness of this finding in the next section using a matching approach before explaining our perception.

Table 4: Estimated Mean WTP per Month on Top of Current Bill

\begin{tabular}{|c|c|c|c|}
\hline & $\begin{array}{l}\text { Expected WTP } \\
\text { (Naira) }\end{array}$ & Lower bound & Upper bound \\
\hline Double bound & $\begin{array}{l}1,058.81 \\
\text { (US\$6.82) }\end{array}$ & $\begin{array}{l}971.69 \\
\text { (US\$6.26) }\end{array}$ & $\begin{array}{l}1,145.93 \\
\text { (US\$7.38) }\end{array}$ \\
\hline \multicolumn{4}{|c|}{ WTP (Naira) from double-bounded model by consumers' characteristics } \\
\hline & Lagos & Osun & Weighted avg. \\
\hline WTP on top of monthly bills (baseline estimates) & $\begin{array}{l}1,160.72 \\
\text { (US\$7.48) }\end{array}$ & $\begin{array}{l}956.60 \\
\text { (US\$6.16) }\end{array}$ & $\begin{array}{l}1,058.81 \\
\text { (US\$6.82) }\end{array}$ \\
\hline Backup households & $\begin{array}{l}1,256.36 \\
\text { (US\$8.09) }\end{array}$ & $\begin{array}{l}1,052.24 \\
\text { (US\$6.78) }\end{array}$ & $\begin{array}{l}\text { 1,154.44 } \\
\text { (US\$7.44) }\end{array}$ \\
\hline Non-backup households & $\begin{array}{l}1,036.23 \\
\text { (US\$6.67) }\end{array}$ & $\begin{array}{l}832.11 \\
\text { (US\$5.36) }\end{array}$ & $\begin{array}{l}934.31 \\
\text { (US\$6.02) }\end{array}$ \\
\hline Prepaid customers & $\begin{array}{l}1,530.45 \\
\text { (US\$9.79) }\end{array}$ & $\begin{array}{l}1,326.37 \\
\text { (US\$8.54) }\end{array}$ & $\begin{array}{l}1,428.55 \\
\text { (US\$9.20) }\end{array}$ \\
\hline Post-paid customers & $\begin{array}{l}1,112.03 \\
\text { (US\$7.16) }\end{array}$ & $\begin{array}{l}907.92 \\
\text { (US\$5.85) }\end{array}$ & $\begin{array}{l}1,010.48 \\
\text { (US\$6.51) }\end{array}$ \\
\hline
\end{tabular}

Note: Official exchange rate at the time of the survey was N155.25: US\$1.

\footnotetext{
${ }^{20}$ To compute the average kWh of electricity consumed per hour, we divided the average monthly electricity consumption by the average hours of electricity availability per month. This yielded an average of $0.71 \mathrm{kWh}$ per hour.

${ }^{21}$ Nigeria currently operates a multi-tariff rate-per-kWh system that ranges from N12.30 to N16.00 for residential consumers, depending on their category. The categories used by the service provider include whether a house is only residential, somewhat commercial, highly commercial, etc. The average tariff for our sample at that time was N13.01.

${ }^{22}$ This difference is obtained by comparing the weighted WTP amount for backup households with that of non-backup households.
} 


\subsection{Alternative Estimation Method - A Matching Approach}

In this section, we use a matching method as an alternative estimator. One concern is that the impact of owning a generator (on WTP) may not be homogenous across households, but, rather, may vary as a function of the (observed and unobserved) characteristics of the households. For instance, generators may be less productive in (or less useful to) a household that either lacks the financial capacity to (fully) finance the operation of the generator (e.g., due to the inability to fuel the generator) or whose energy demand is low. In this case, simple double-bounded model regression estimates may be biased. The first bias arises when there are some households that have invested in backup generation, but there are no comparable households without such investments, and vice versa. The second bias may arise from different distributions of the vector of observable variables $(Z)$ that affect WTP within the two groups of households.

Matching methods eliminate these two potential sources of bias by pairing backup households (treatments) with non-backup households (controls) that have similar observed characteristics. The first source of concern can be eliminated using observations in the treatment and control groups over the region of common support in the distribution of $Z$, whereas the bias arising from different distributions of $Z$ between treated (backup) and untreated (non-backup) households within this common support can be eliminated by reweighting the control group observations (i.e., by using kernel matching). The underlying assumption in matching estimation is that, conditional on the observed characteristics $Z$, the counterfactual outcome distribution of the treated units is the same as the observed outcome distribution of the units in the control group.

The objective in matching is to construct a group by finding non-backup households (controls) that have observed characteristics $Z s$ similar to those of the backup households (treatments). Rosenbaum and Rubin (1983) have shown that matching treated and untreated subjects on the basis of $Z s$ is similar to matching them using a balancing score $B(Z)$. The balancing score is the propensity score that gives the conditional probability of receiving treatment (i.e., owning a backup), given the pre-treatment values of the vector $Z$ - that is, $P(Z)=$ $P(T=1 \mid Z)$. Thus, the matching technique assumes that, conditional on $P(Z)$, the counterfactual outcome distribution of the treated subjects is the same as the observed outcome distribution of the controls. This propensity score-matching procedure reduces the potential problem, from matching on high-dimensional vector $Z$ of the observed characteristics to matching on a scalar.

We estimate propensity scores from a logit model of the probability that a household owns a backup generator conditional on the household's and service's characteristics, and then, conditional on the probability, 
we predict the WTP differential between the backup and non-backup households. ${ }^{23}$ We identify control and treatment observations on a common support as follows. We exclude all control observations whose propensity scores are less than the propensity score of the treatment households at the 10th percentile of the treatment propensity score distribution, and exclude all treatment observations whose propensity score is greater than the propensity score of the control observation at the 18th percentile of the control distribution. Then, we estimate differences in WTP on the observations that lie on this common support, using both the nearest neighbour and kernel density weighting matching estimators.

Table 5 presents the WTP differential obtained from the two matching algorithms. The results from both the kernel and nearest neighbour matching estimators confirm our earlier findings. On average, the results show that households owning backup generators would be willing to pay between N211.42 (US\$1.36) and N296.71 (US\$1.91) - in additional WTP per month - more than comparable non-backup households. This finding is robust to different specifications of the propensity score and different matching estimators. Specifically, we found that the common support estimates are similar to full sample results: the average effects of using a backup generator, using the nearest neighbour and kernel algorithms, were N301.42 (US\$1.94) and N211.97 (US\$1.37) respectively. When comparing households with similar characteristics, the households owning backup generators would be willing to pay more than households that had not invested in backup generation. These findings reinforce the earlier findings and confirm that self-generation is positively associated with WTP. To examine the sensitivity of our findings to unobserved components, we examine the degree to which our findings might be affected by the unobserved components. The results suggest that, indeed, selfgeneration is positively related to WTP - see Appendix D for details on the procedures and the results obtained from the test for unobserved component effects.

Table 5: Differences Between Backup and Non-Backup Households' Stated Monthly WTP Amount - Matching Methods

\begin{tabular}{l|lllc}
\hline & \multicolumn{2}{|c}{ Full sample } & \multicolumn{2}{c}{ Common support } \\
\hline & $\begin{array}{l}\text { Nearest } \\
\text { neighbour }\end{array}$ & Kernel estimator & $\begin{array}{l}\text { Nearest } \\
\text { neighbour }\end{array}$ & Kernel estimator \\
\hline $\begin{array}{l}\text { Average treatment effect } \\
\text { on the Treated }\end{array}$ & 296.71 & 211.42 & 301.42 & 211.97 \\
& $(109.38)$ & $(100.16)$ & $(109.42)$ & $(99.21)$ \\
\hline
\end{tabular}

Notes: Bootstrapped standard errors in parentheses; 500 replications used.

\footnotetext{
${ }^{23}$ We estimate several logit regressions and select the one that satisfies the balancing properties assumption.
} 


\section{MARGINAL COST OF OUTAGE AND WTP}

\subsection{Self-Generation (Outage) Costs and WTP - A Simple Method}

The key finding from the analysis of WTP in the previous section is that households engaging in selfgeneration would be willing to pay more than those without. An obvious question that arises from this finding is: What does it cost to generate a $\mathrm{kWh}$ at home? Or, put differently: What is the cost of outage to households? This question is pertinent because the cost of backup generation would serve as the immediate measure of the cost of the electricity service that is available to backup households but not available to non-backup households. An explanation for the finding that backup households express a higher WTP than non-backup households could be that self-generation is more expensive, which they take into account when making WTP decisions. We investigate how much it costs a household to generate its own electricity as a way of understanding why backup households would express greater WTP. For this analysis, we use the information on backup generation reported by households in our sample. During the survey, respondents were asked to indicate whether they had a backup generator. They were also asked to provide information on the purchase and operating costs, year of acquisition and capacity of the generator. ${ }^{24}$ In total, around 55 per cent of the sampled households reported owning a backup generator.

In making a decision, households have to choose the optimal amount of backup power by considering a generator's energy load and the welfare impact of the unserved energy. A rational household will maximise the expected marginal benefits from generating a kWh from its plant by equating at the margin the expected cost of generating the $\mathrm{kWh}$ to the expected benefit from that $\mathrm{kWh}$. This benefit consists of the utility derivable from the continued lighting, television watching, radio listening, cooking, and cooling (even if partial) made possible by self-generated electricity, and the reduction in welfare loss that would have resulted from power interruptions. The marginal cost of self-generation serves as an estimate for marginal outage costs because the expected marginal gain from self-generation equals the expected welfare loss from the $\mathrm{kWh}$ not supplied by the utility provider.

A household's cost of generating its own electricity is formed of two components. The first is the annual capacity cost of a generator. This cost is denoted by $b G$, where $G$ represents the generator's capacity in $\mathrm{kW}$. The second cost component is the operating expenses - the variable cost per $\mathrm{kWh}$. This is mainly the cost of fuel and is practically constant, given the assumption that the generator is used at full capacity during power

\footnotetext{
${ }^{24}$ Capacity was reported in $\mathrm{kVA}$ but converted into $\mathrm{kW}$, given that $1 \mathrm{kVA}=0.8 \mathrm{~kW}$ at full capacity.
} 
outages. Thus, the yearly variable cost will be $v \pi G$, where $v$ is the fuel cost per $\mathrm{kWh}$ and $\pi$ (measured in hours) is the expected total hours, per annum, during which a household self-generates electricity. ${ }^{25}$ The total annual expected cost (in $\mathrm{kW}$ ) is the sum of the yearly generator and variable cost:

$C(G)=b G+v \pi G$

The expected marginal cost (US\$/kWh) of self-generated electricity can be written as:

$C^{\prime}(G)_{k W h}=\frac{b^{\prime} G}{\pi}+v$

Equation (4) can be used to compute the marginal cost of self-generation using data on a household's acquisition and running cost of self-generation, and the duration of power outages. To achieve this result, values for $b^{\prime}, \pi$ and $v$ must be obtained. This method was proposed for the estimation of firms' (marginal) outage costs by Bental and Ravid (1982). Applying Equation (4) to data on backup generation allows us (using reasonable assumptions) to estimate the (marginal) cost of self-generation from the observed information about the acquisition and running costs of generating capacity, as well as from data on power outages. ${ }^{26}$ The unit cost of capital of self-generated electricity, $b^{\prime}$, depends on price schedules for generators, tax and depreciation rules, and interest rates. Original price schedules and data on the year of acquisition were reported during the survey. First, the price schedules were converted to 2012 prices using the corresponding values of the consumer price index. We then obtained the capital cost per $\mathrm{kW}$ of installed capacity (assuming no tax rules, a 15-year life span and an interest rate of 10 per cent). ${ }^{27}$ For $\pi$, we used the generator operating hours reported by backup households. $^{28}$

Table 6 presents the estimated costs of self-generation (i.e., outage costs) based on Equation (4), the average electricity prices and the estimated average WTP amount by backup households. The estimates show that the average WTP is higher than the grid electricity price, but smaller than the marginal cost of selfgeneration by backup households. The key result is that households pay US\$0.08/kWh for grid supplies but are willing to pay US $\$ 0.16 / \mathrm{kWh}$, since it costs up to US\$0.41/kWh to generate electricity at home. There are two

\footnotetext{
${ }^{25}$ Unlike previous studies which used outage times, we use generator operating hours reported by households. This gives better estimates of outage cost than outage times because some generator owners might not operate their generators throughout the outage period. A factor that can limit generation operation is the budget constraint.

${ }^{26}$ This measure of marginal cost does not account for any additional welfare loss that may result from incomplete backup. Such welfare loss may include damage to home appliances and food spoilage.

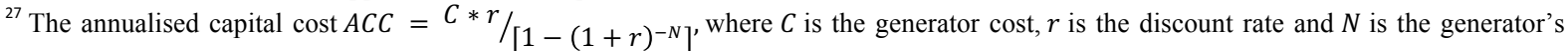
life span.

${ }^{28}$ Instead of making an assumption that households operate their generators throughout the outage periods, we use the reported operating hours. Using the actual operating time reported by consumers improves the accuracy of the estimates because several factors (e.g., budget constraint) might prevent them from running their generators throughout outage period. Thus, using outage time based on the assumption that households operate their generators throughout outage period would underestimate the generation cost.
} 
possible explanations for this finding. The first intuition is that backup households do run their generator to power some of their most valuable appliances, and the stated WTP is for the non-operated appliances that are less valuable; thus, they spend a higher amount on running the most valuable appliances but would be willing to pay less than the cost of running the most valuable appliances to run the less valuable, non-operated appliances.

The second possible explanation relates to the WTP behaviour of both the backup and non-backup households: the backup households would be willing to pay more than non-backup households because the marginal cost of self-generation (i.e., outage cost), which is more expensive, serves as an immediately observable measure of WTP that is not available to non-backup households. In other words, backup households used the marginal cost of self-generation as their reference price upon which their WTP decision was based. Intuitively, backup households are willing to pay more than non-backup households because their reference prices (i.e., self-generation costs) are higher than those of non-backup households (who pay the grid price). However, they are willing to pay less than their reference prices (self-generation costs) in order to avoid transaction disutility. ${ }^{29}$

Table 6: Comparison of the (Marginal) Costs of Self-generation and the Expected WTP Amount by Backup Households

\begin{tabular}{l|lllll}
\hline & $\begin{array}{l}\text { (Marginal) } \\
\text { variable cost } \\
(\text { per } \mathrm{kWh})\end{array}$ & $\begin{array}{l}\text { Unit capital cost } \\
(\text { per } \mathrm{kWh})\end{array}$ & $\begin{array}{l}\text { Total }(\text { marginal) } \\
\text { cost }(\text { per } \mathrm{kWh})\end{array}$ & $\begin{array}{l}\text { Grid price } \\
\text { (average) (per } \\
\mathrm{kWh})\end{array}$ & $\begin{array}{l}\text { Expected avg. WTP } \\
\text { amount per } \mathrm{kWh}\end{array}$ \\
\hline State & $59.07(\mathrm{US} \$ 0.38)$ & $2.50(\mathrm{US} \$ 0.02)$ & $61.57(\mathrm{US} \$ 0.40)$ & $13.28(\mathrm{US} \$ 0.09)$ & $25.30(\mathrm{US} \$ 0.16)$ \\
Osugos & $52.10(\mathrm{US} \$ 0.34)$ & $4.21(\mathrm{US} \$ 0.03)$ & $56.32(\mathrm{US} \$ 0.36)$ & $12.48(\mathrm{US} \$ 0.08)$ & $23.30(\mathrm{US} \$ 0.15)$ \\
Overall & $57.03(\mathrm{US} \$ 0.37)$ & $3.00(\mathrm{US} \$ 0.02)$ & $60.03(\mathrm{US} \$ 0.39)$ & $13.01(\mathrm{US} \$ 0.08)$ & $24.30(\mathrm{US} \$ 0.16)$ \\
\hline
\end{tabular}

Note: Official exchange rate at the time of the survey was N155.25: US\$1.

\subsection{Marginal Cost of Reliability Improvement due to Backup Generation - A Regression Approach}

In this section we set up a household's optimisation problem and estimate the marginal cost of (i.e., the revealed WTP for) reliability improvement due to backup generator ownership using data on households' investment in backup generation. ${ }^{30}$ This follows the approach by Caves et al. (1992), Hartman et al. (1991) and Matsukawa and Fujii (1994).

Let $A$ represent the per kWh cost with backup generation ownership and be equal to the sum of the per $\mathrm{kWh}$ cost of owning and operating a backup generator, $G$, the per kWh rate charged by the local supplier, $P$, and the per kWh outage cost $X$ which depends on the reliability with backup and household characteristics. For a

\footnotetext{
${ }^{29}$ See Thaler (1985) and Weaver and Frederick (2012) for a detailed discussion on consumer behaviour and reference prices.

${ }^{30} \mathrm{We}$ thank an anonymous referee for suggesting this part of analysis be included.
} 
non-backup household, let $B$ represent the per kWh cost without backup generation ownership and be equal to the sum of the per $\mathrm{kWh}$ rate charged by the local supplier, $P$, and the per $\mathrm{kWh}$ outage cost $Y$ which depends on the grid reliability and household characteristics. A household adopts backup generation if $A<B$, implying $(G+X-Y)<0$ because $P$ is the same for $A$ and $B$. Thus, data on backup generation ownership can be used to infer the WTP for a marginal reliability improvement.

Suppose that a household $i^{\prime}$ s utility function is represented by a binary choice model as:

$$
U_{i}=\alpha G_{i}+\beta R_{i}+\lambda \theta_{i}+\varepsilon_{i}
$$

where $G$ is as previously defined, $R$ denotes the reliability improvement due to backup generation ownership, $\theta$ represents all other controls which might affect the household's utility, while $\varepsilon$ is the error term. By differentiating equation (5) and set $d U=0$, the (revealed) WTP for (or the marginal cost of) a marginal reliability improvement due to backup generation is $d G / d R=-\alpha / \beta$. Using data on the per $\mathrm{kWh}$ cost of owning and operating a backup generator, generator's operating hours, the grid reliability, and other control variables including household demographics, we estimate equation (5) by maximum likelihood estimator. On average, the marginal cost of (or marginal WTP for) reliability improvement due to backup generation is estimated to be N52.54 (US\$0.34) per kWh (see Table 7). ${ }^{31}$

Table 7 summarizes the WTP obtained from the survey data analysis (i.e., based on the stated preference), the estimated marginal costs of reliability from backup generation (i.e., based on the two forms of the revealed preference approach) and the grid electricity prices. On average, the estimated marginal costs of reliability improvement (i.e., a measure of the revealed WTP) are more than double the stated WTP and are more than four times the (currently subsidised) grid electricity prices. The results show that although households would be willing to pay roughly twice the current tariff rates to enjoy better reliability, their stated WTP is substantially lower than the marginal cost of improved reliability from self-generation.

\footnotetext{
${ }^{31}$ For reasons of space we do not report the regression results from which this figure was estimated.
} 
Table 7: Comparison of Estimated Outage Costs/WTP Per kWh

\begin{tabular}{|c|c|c|c|c|}
\hline State & $\begin{array}{l}\text { Stated Preference } \\
\text { Stated WTP } \\
\end{array}$ & $\begin{array}{l}\text { Revealed Prefe } \\
\text { Simple method }\end{array}$ & $\begin{array}{l}\text { Marginal cost } \\
\text { Regression method }\end{array}$ & Grid price (average) \\
\hline Lagos & $25.30(\mathrm{US} \$ 0.16)$ & $61.57(\mathrm{US} \$ 0.40)$ & $63.37(\mathrm{US} \$ 0.41)$ & $13.28(\mathrm{US} \$ 0.09)$ \\
\hline Osun & 23.30(US\$0.15) & $56.32(\mathrm{US} \$ 0.36)$ & 42.39(US\$0.27) & 12.48(US\$0.08) \\
\hline Overall & $24.30(\mathrm{US} \$ 0.16)$ & 60.03(US\$0.39) & $52.54(\mathrm{US} \$ 0.34)$ & 13.01(US\$0.08) \\
\hline
\end{tabular}

Note: Official exchange rate at the time of the survey was N155.25: US\$1.

The extent to which our results can be compared to estimates obtained in studies conducted in other developing countries is limited for several reasons. First, not many studies have used the revealed preference method (e.g., backup generation) to estimate the value of unreliability at household level. Second, the majority of studies that estimate households' WTP for reliability in developing countries report the WTP per hour instead of per kWh (see for example Abdullah and Mariel, 2010; Ozbafli and Jenkins, 2016). Nevertheless, our results are compared to those of studies that report their estimates in per kWh, regardless of the level of development of the countries studied. Our stated WTP estimates, which range between US\$0.15/kWh-0.16/kWh depending on backup ownership and the state of residence, are reasonably close to US\$0.14/kWh (2013 prices) obtained in Twerefou (2014)'s study of Ghanaian households. However, our estimated stated WTP (i.e., US\$0.15/kWh$0.16 / \mathrm{kWh}$ ) and the marginal costs of reliability from self-generation (i.e., US $\$ 0.27-0.41 / \mathrm{kWh}$ ) are substantially lower than US\$2.99-16.44/kWh (2013 prices) obtained in a study of Israeli households (Beenstock et al., 1998). Meanwhile our estimates fall within the lower end of the wide range of US\$0.04-26.70/kWh (2013 prices) reported in Caves, Herriges, and Windle (1990), but are clearly lower than US\$2.79-7.23/kWh (2013 prices) obtained in a study of California residential consumers (Layton and Moeltner 2005).

The differences in the WTP and outage cost estimates may be attributed to different factors including valuation techniques, econometric methods, functional formulation, service attributes, and socio-economic and demographic variables included in the econometric analyses. The level of trust in the electricity authority might also account for the differences in the WTP values (Abdullah and Mariel, 2010). In particular, the WTP is often lower in countries where previous price increases were not matched with improved service quality (Townsend 2000).

\section{CONCLUSION AND RECOMMENDATION}

We have studied consumers' WTP and explored the role of in-house generation in households' WTP for electricity reliability in Nigeria. We found that having a generator tended to increase (rather than decrease) households' WTP. This is despite the fact that having and using a generator could potentially reduce the welfare 
impact of power unreliability. Further exploration of the link between the marginal (outage) cost of selfgeneration and backup households' WTP decisions, however, revealed that the significantly high cost of selfgeneration (outage cost) might be responsible for the observed WTP behaviour of the backup households. The decision by backup households to pay more appears to be driven by rational behaviour, because paying more to enjoy reliability would mean having extra benefits - i.e., enjoying extra reliability at a lower cost than that of self-generation.

Moreover, the finding that backup households are willing to pay more than non-backup households and that what they are willing to pay is less than the cost of self-generation is consistent with the transaction utility/value theory (Thaler 1985). The intuition behind this observed behaviour is that backup households are willing to pay more than non-backup households because their average reference price (i.e., self-generation cost) is higher than the average reference price (i.e., current tariff) for non-backup households due to their experience with self-generation costs. Backup households, however, express a WTP that is lower than their self-generation costs in order to make some gains by paying an amount below their reference price (self-generation cost).

A number of policy recommendations emerged from our findings. Assessing how households value improved services is important for understanding consumer preferences for proposed service improvements, which, in turn, is essential for making decisions regarding the planning of electricity service reliability. For this study, the estimated mean WTP shows that Nigerian households, regardless of their income, would be willing to pay an extra amount (up to 86 per cent) above the current tariff for improved service quality. This implies that households would value the reliability of a more expensive supply above the current highly subsidised tariffs that come with low quality.

To the extent that consumer WTP can be inferred to be a measure of the welfare impact of unreliability on consumers, it is therefore incumbent on the government or regulator to ensure a steady increase in the quality of electricity supply and then recover the costs through higher charges. One way forward would be for the government to consider optimal tariffs that are cost recovering for new investment and regulatory incentives for reliability. The implementation of such price reforms would encourage private investments in electricity provision and raise reliability. At the very least, the 'open' subsidy regime currently operated needs to be replaced by targeted subsidies designed to protect only the low-income and vulnerable groups. This could be in the form of cash transfer to deserving households based on a set benchmark. Alternatively, the government could use the subsidies removed from electricity tariffs to finance another benefit scheme (e.g., a school feeding 
programme), or use it to subsidise the uptake of environmentally friendly renewable energy generation, including solar photovoltaic power plus storage as an alternative to both the grid and diesel generators.

The estimation of outage (self-generation) cost in this study provides insights into the cost imposed on households of poor electricity services and the households' preferences for improved electricity service performance, which, in turn, can help policymakers in terms of reliability investment planning. The cost imposed on households by unreliable power is very high, and many households demonstrate high WTP for reliable power through stated preferences and their investments in (expensive) self-generation. There is therefore a market for more expensive and higher quality power supply. It should be possible to strike a bargain between the government and private sector to the effect that households pay higher price for grid power to fund investments that will make their power supply more reliable. Lastly, another policy option for the government is to implement rising block tariffs, where prices are differentiated over a set block of units such that the first block unit is priced lower compared to the subsequent consumption block(s). It was found that ownership of a backup generator is correlated with ownership of household appliances. Thus, since those who own many appliances are more likely to consume more energy, rising block tariffs are a plausible option for policymakers to consider.

This study is not without limitations, however. The issue of endogeneity and the limited nature of our dataset constitute two potential limitations to the analyses presented in this paper. It is possible that engagement in self-generation is endogenously determined. For example, certain factors (e.g., energy demand) may jointly influence both the decision to engage in backup generation and WTP. However, instrumental variable (IV) methods allow consistent estimation when there is an endogeneity problem, though the credibility of the estimates from a regression using IV methods hinges on the selection of suitable instruments that do not violate the underlying IV conditions. ${ }^{32}$ If these conditions are violated then the IV method may create more problems than it solves. Since we could not find suitable IVs for our analyses, we chose not to use IV methods in this study. The analyses, however, deal to some extent with this potential problem by estimating an alternative specification by (1) using fuel cost per hour instead of a generator ownership dummy, and (2) applying matching methods and testing for unobservable components' effects. Nevertheless, future studies should consider an IV regression specification using credible instruments when examining the effects of self-generation on WTP. Finally, a nationally representative survey should be considered in order to overcome the limitation of a restricted dataset.

\footnotetext{
${ }^{32}$ The two main requirements for using an IV are: (1) the instrument must be correlated with the endogenous explanatory variables, conditional on the other covariates; and (2) the instrument cannot be correlated with the error term in the explanatory equation - that is, the instrument cannot suffer from the same problem as the original predicting variable.
} 


\section{ACKNOWLEDGEMENTS}

I would like to thank Michael Pollitt and Paul Kattuman for reading and discussing numerous drafts of this paper. I thank David Reiner, Michelle Baddeley, David Newbery and Jevgenijs Steinbuks for their thoughtful comments. Valuable contributions from anonymous referees are appreciated. I also thank the participants at the various Energy Conferences at which this paper has previously been presented for their useful comments. Finally, the financial support of Cambridge Judge Business School, the University of Cambridge and the African Economic Research Consortium (AERC) is gratefully acknowledged. The usual disclaimer applies.

\section{APPENDICES}

\section{Appendix A: Nigeria Electricity Sector - Overview}

In spite of various reform steps that have been undertaken in the Nigeria electricity sector, not much progress has been recorded. At $6500 \mathrm{MW}$, the total installed capacity of Nigeria's public electricity grid meets $30 \%$ of requirements, at best, and only about half of this available capacity is often generated (EIA, 2012), due to ageing and poorly maintained generating, transmission and distribution facilities (World Bank 2003). Figure A.1 shows the implied installed capacity factor, per capita net generation and consumption of electricity in Nigeria from 1980-2012. The implied installed capacity factor indicates that the Nigeria power plants had been operating less than $50 \%$ of full capacity until 2012 when it attained the all-time high capacity factor of just $51 \%$. This implies that despite having inadequate installed capacity to cater for its population, the performance of the meagre available capacity has remained abysmally poor. The country's per capita electricity consumption remains less than $150 \mathrm{kWh}$ per annum. The implication of this inadequate generating capacity is that a large number of Nigerians do not have access to electricity and that those who have access still battle with unreliable supply and frequent blackouts. Apart from the lack of access to electricity for a large proportion of the population, which currently stands at about $60 \%$ (see Eleri et al., 2012), constant power outages remain a common experience among Nigeria's electrified households. The average Nigerian household experiences power outages more than three times a day. These outages last about four hours on average. ${ }^{33}$

\footnotetext{
${ }^{33}$ The outage time ranges from eight minutes to 22 hours a day.
} 


\section{Nigeria Electricity Supply}

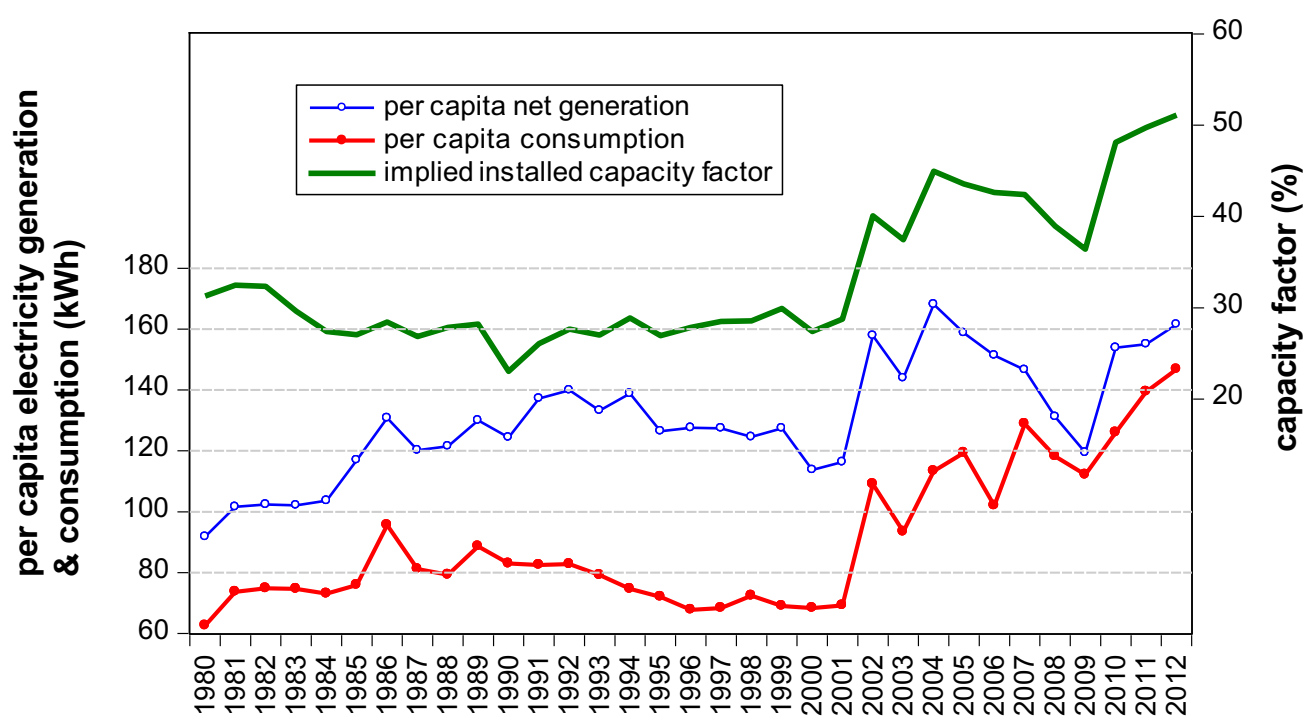

Source: Energy Information Administration: http://www.eia.gov/countries/country-data.cfm?fips=NI\#elec

Given this high level of unreliability, households in Nigeria have adopted different strategies to cope with the poor public provision. Some of these response adjustments include the use of kerosene lamps, kerosene stoves, rechargeable lamps, gas lamps, torches and self-generation through backup generators. ${ }^{34}$ Although many of these responses are observable among Nigerian households, the most common and closest substitute for electricity from the public grid is self-generation. ${ }^{35}$ Many households now operate small generators with capacity ranging from $0.4 \mathrm{~kW}$ to $8 \mathrm{~kW}$. However, it is not clear whether this self-generation undermines households' WTP for service improvements from the national grid.

\footnotetext{
${ }^{34}$ These were the alternatives reportedly used by respondents during the survey when we asked them how they manage to cope with blackouts.

${ }^{35}$ More than $50 \%$ of households in our sample indicated that they had at least one generator, with some households having as many as three generators. Even among the households that stated that they didn't have a generator, many of them told us that their fellow tenants have them.
} 
Appendix B: Effects of Backup Ownership on WTP

Table B1: Effects of backup ownership on WTP

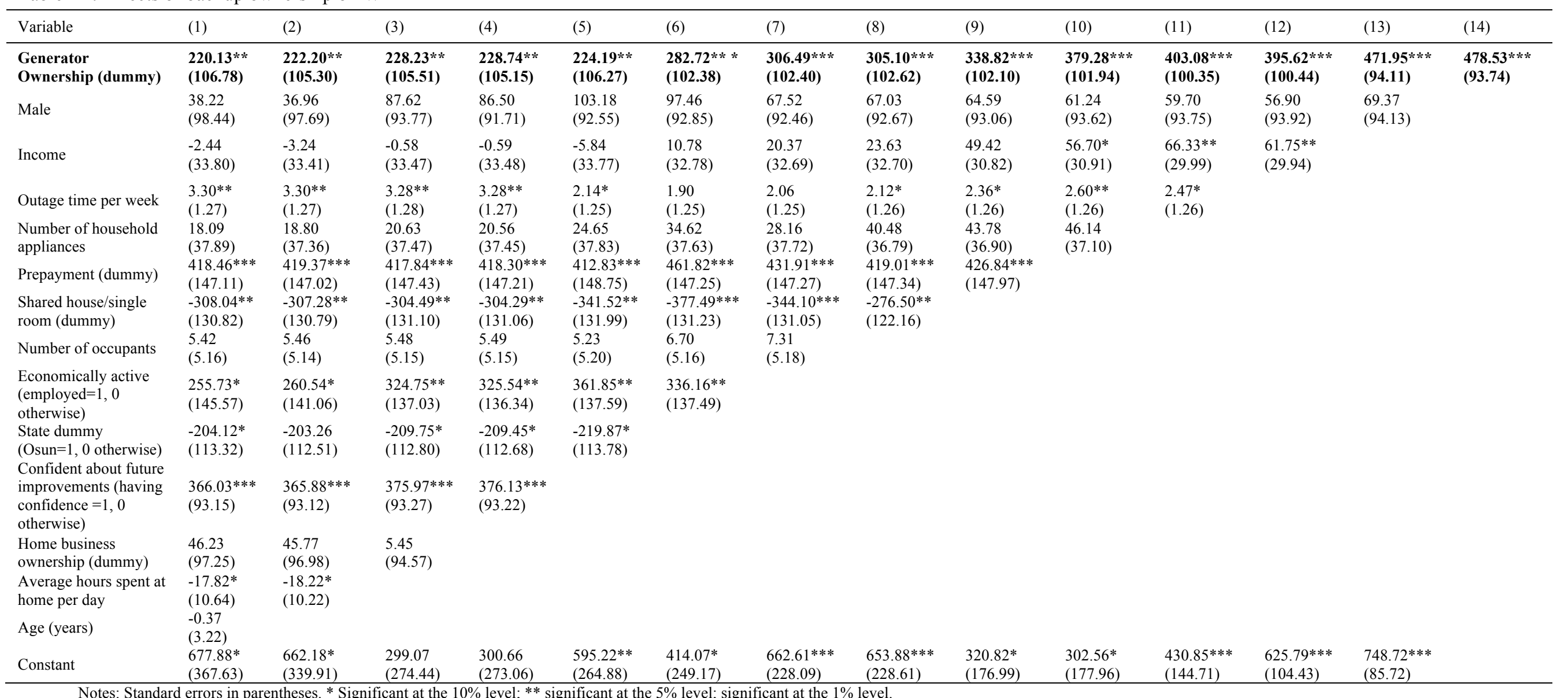




\section{Appendix C: Protests in WTP}

One problem often associated with CVM is protest zeros or zero bids. Protest zeros or zero bids are honest responses provided by low-income respondents and those who hold negative views about the good or service being evaluated or refuse to participate in the study (Mitchell and Carson, 1989). Generally, a protest zero is where respondents state their willingness to pay nothing for a good or service even though they may hold a value for it. Protest zeros are a source of concern (Mitchell and Carson, 1989) because researchers often need to distinguish between those respondents who hold a value but cannot afford to pay and those who are not willing to pay despite holding a value for the good or service in question. For dichotomous-choice questions, protest zeros are of particular concern because a 'no' or 'no-no' response may be misinterpreted as a willingness to pay less than the stated amount rather than as a protest. Hence, it is necessary to introduce a follow-up question to identify protest-zero respondents (Boyle 2003).

As highlighted by Halstead, Luloff and Stevens (1992), three principal means are commonly used to deal with protest zeros in the literature: (i) drop them from the data set; (ii) assign protest bidders mean WTP values based on their socio-demographic characteristics relative to the rest of the sample group; or (iii) treat the protest bids as valid zero bids and include them in the data set. A major concern with the first approach is the loss of potentially useful information as well as the likely tendency for self-selection bias (Halstead, Luloff, and Stevens 1992). The second method suffers from the deviation problem: estimated WTP based on this approach may totally deviate from the true value if the socio-demographic characteristics of zero-bidders are different from those of the general population.

A major concern with the third approach (i.e. the inclusion of protest zeros as legitimate bids) is that it can downwardly bias the mean WTP estimates. Despite this concern, however, it has been argued that protest bids (if they exist) 'should be considered legitimate WTP bids as respondents are essentially valuing a proposed policy, not just a commodity' (McGuirk, Stephenson and Taylor, 1989, pp 1-2). Following this argument, we included 'no-no' responses in the estimates of WTP presented in the main paper. However, in order to ascertain the level of protest in our study, we introduced an open-ended follow-up question for respondents who answered 'no-no' to the proposed bid questions. The open-ended question asked was 'You have answered both questions A9 and A11 as 'no-no'. Then, how much would you be willing to pay ?' We found that $19.8 \%$ of those who answered 'no-no' to the bid questions (representing $4.1 \%$ of the total sample) would be willing to pay nothing. A non-response rate of around $20 \%$ to $30 \%$ is common (Mitchell and Carson, 1989), therefore the non-response rate was within acceptable limits under which valid WTP values can be estimated. Moreover, the majority of these respondents were from low-income households, suggesting that their stated zero amounts reflected their inability to pay rather than a protest (Figure C.1). 
Figure C.1: Proportion of zero responses by income category

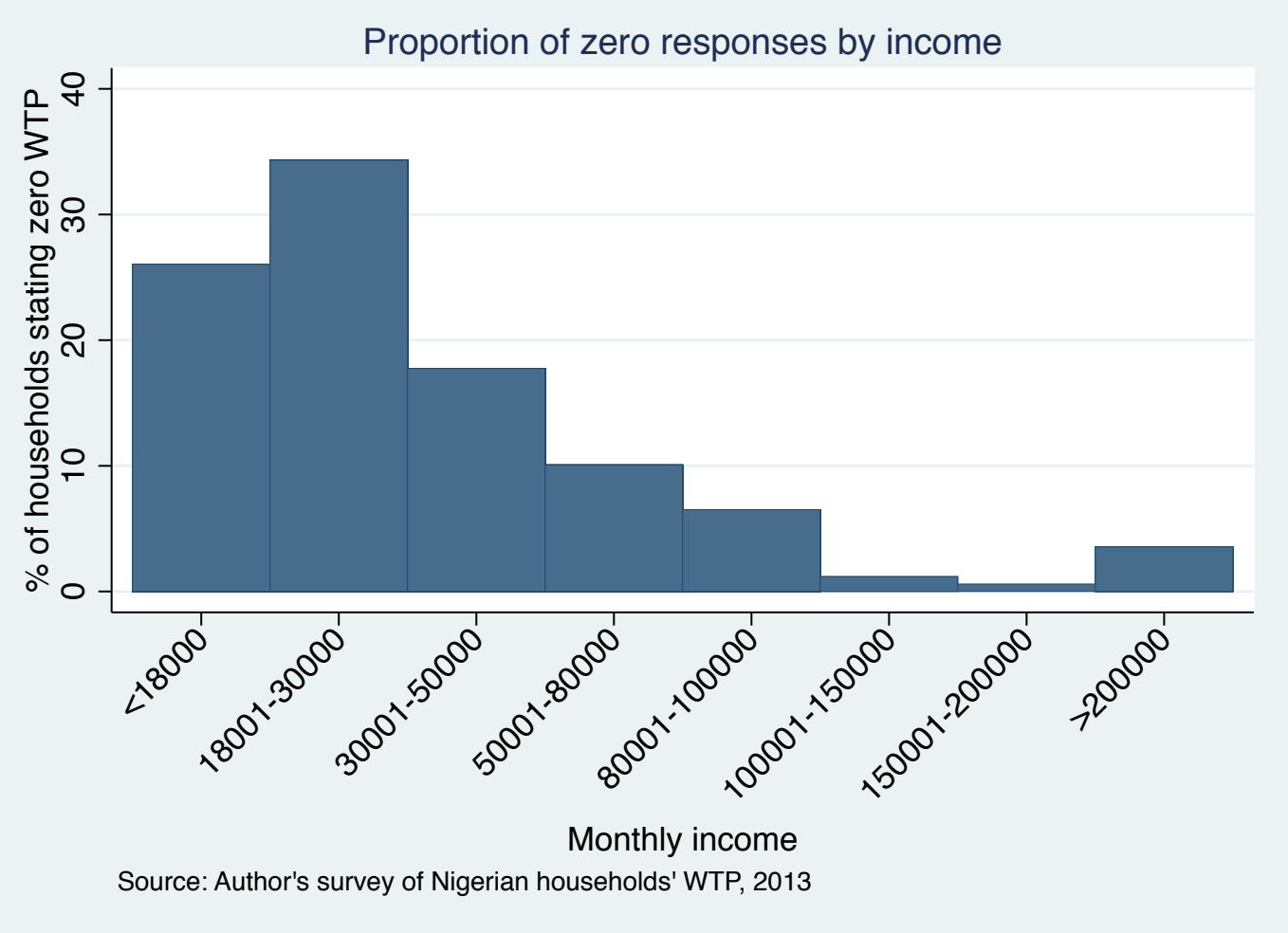

We also estimated the probability of stating zero WTP using the follow-up question responses for the 'no-no' response sample. This was done to better examine the factors responsible for stating zero WTP as a mean of further investigating the presence of protest in our analysis. The results showed that income was the main determinant of stating a zero bid (Table C.1), implying that our analysis was not or was minimally susceptible to protest.

Table C.1: Probability of stating zero WTP

\begin{tabular}{l|l|l|l}
\hline Variable & Coefficient & Variable & Coefficient \\
\hline Male & 0.24 & Prepayment & 0.14 \\
& $(0.32)$ & & $(0.60)$ \\
Generator & 0.39 & State - Osun & -0.25 \\
& $(0.36)$ & & $(0.27)$ \\
Income group & $-0.36^{* * *}$ & Consumer confidence & -0.35 \\
& $(0.13)$ & & $(0.30)$ \\
Outage time (hrs) per week & $-0.01 *$ & Home business ownership & 0.23 \\
& $(0.004)$ & & $(0.30)$ \\
Shared house/single room & -0.23 & Hours spent at home & -0.05 \\
& $(0.40)$ & & $(0.04)$ \\
Number of household appliances & 0.15 & Age & 0.01 \\
& $(0.12)$ & & $(0.01)$ \\
Number of occupants & -0.01 & Constant & $(1.25$ \\
& $(0.02)$ & & \\
Economically active & -0.39 & & \\
\hline Number of observations & $(0.35)$ & & \\
Log-likelihood & 138 & \\
Notes: Standard errors in parentheses. * Significant at the $10 \%$ level; ** significant at the $5 \%$ level; significant at the $1 \%$ level.
\end{tabular}


Table C. 2 presents the estimates from the double-bounded model when respondents ( $4 \%$ of the sample) who stated zero WTP to the follow-up open ended question were excluded. The signs and significant levels of covariates were similar to the estimates (without correcting for zero bids) reported in the main text. However, the mean WTP estimate is slightly higher (about 6\%) than the mean WTP value for all sample (including zero bids) reported in the main paper. This change indicates that, to some extent, zero bids in the estimates slightly lowered the WTP values reported in the main paper.

Table C.2: Results for double-bounded model (excluding zero bids)

\begin{tabular}{|c|c|c|c|}
\hline Dependent variable: WTP (Naira) & Coefficient & Variable & Coefficient \\
\hline Male & $\begin{array}{l}60.85 \\
(96.51)\end{array}$ & $\begin{array}{l}\text { Eco. Active (employed }=1,0 \\
\text { otherwise) }\end{array}$ & $\begin{array}{l}121.71 \\
(146.16)\end{array}$ \\
\hline Generator Ownership & $\begin{array}{l}157.42 * * \\
(74.47)\end{array}$ & $\begin{array}{l}\text { State dummy (Osun=1, } 0 \\
\text { otherwise) }\end{array}$ & $\begin{array}{l}-232.38 * * \\
(110.83)\end{array}$ \\
\hline Income group & $\begin{array}{l}-11.28 \\
(33.00)\end{array}$ & Consumer confidence & $\begin{array}{l}310.58 * * * \\
(91.42)\end{array}$ \\
\hline Outage time (hours) per week & $\begin{array}{l}2.71 * * \\
(1.25)\end{array}$ & Home business (dummy) & $\begin{array}{l}103.47 \\
(95.72)\end{array}$ \\
\hline Number of household appliances & $\begin{array}{l}23.69 \\
(37.16)\end{array}$ & Hours spent at home per day & $\begin{array}{l}-21.96 * * \\
(10.48)\end{array}$ \\
\hline Prepaid customer & $\begin{array}{l}385.67 * * * \\
(143.36)\end{array}$ & Age & $\begin{array}{l}0.59 \\
(3.18)\end{array}$ \\
\hline Shared house/single room & $\begin{array}{l}-326.82 * * \\
(128.20)\end{array}$ & Constant & $\begin{array}{l}998.99 * * * \\
(364.52)\end{array}$ \\
\hline Number of occupants & $\begin{array}{l}4.71 \\
(4.30) \\
\end{array}$ & & \\
\hline Log likelihood $=$ & -842.28 & & \\
\hline Number of observations & Mean & Lower bound & Upper bound \\
\hline WTP (Naira) & 1122.02 & 1036.61 & 1207.43 \\
\hline
\end{tabular}

\section{Appendix D}

\section{Robustness Checks: Testing for the effects of Unobserved Components in Matching}

We test whether our finding that having a backup generator tends to increase WTP is affected by unobserved components. One possible reason for the finding is that the key identification assumption - i.e. the assumption that, conditional on all observed household characteristics, whether a household uses a backup generator or not is independent of its WTP without a generator - is invalid. This happens because there exist some unobserved components that affect both whether a household uses a generator and its WTP for service improvements. This could be, for example, a strong but unobserved preference for uninterrupted energy services. For instance, if households that have a strong preference for uninterrupted service supply are both more likely to use a generator and more likely to state a higher WTP amount if they do not have a generator, then the matching estimator may find no negative (or even a positive) effect of having a generator on WTP, even if it does in fact have a negative effect.

We test how much an unobserved behaviour (e.g. preference for regular energy supply) would have to influence a household's decision to use a backup generator and the WTP to significantly change the estimation 
results. The basic idea is that if it can be demonstrated that all configurations of the unobserved behaviour that can reverse the findings can be considered unlikely, we can be confident that the estimates reveal the true effect of using a generator on WTP (rather than the combined effect of using a generator and unobserved behaviour say, having a strong preference for regular supply or higher energy demand).

We used the method first suggested by Ichino et al. (2008) to conduct a robustness test on the results using the following steps. We first made different assumptions to characterise the distribution of the unobserved component $(U)$ in our sample. We then tested under which assumptions of $(U)$ the estimated effect of using a generator on WTP became negative. Finally, we discussed the degree of plausibility of these assumptions. The key assumption made about the unobserved component $(U)$ was that it was independently distributed; i.e. the unobservable component was independent of the observed household characteristics. This allowed us - without loss of generality (see Ichino et al., 2008) - to specify four sets of parameters that characterised the distribution of $(U)$ :

$$
\begin{aligned}
& p_{11}=p(U=1 \mid T=1, Y=1, Z) ; \\
& p_{10}=p(U=1 \mid T=1, Y=0, Z) ; \\
& p_{01}=p(U=1 \mid T=0, Y=1, Z) ; \\
& p_{00}=p(U=1 \mid T=0, Y=0, Z) .
\end{aligned}
$$

These give the probability that $U=1$ in each of the four groups defined by whether or not households have a generator or and whether or not households stated a WTP that was higher than the mean.

To check the effect of a given distribution of $U$, we fixed $p_{11}-p_{00}$ at one given arbitrary (but meaningful) value at a time. We then proceeded by attributing a value of $U$ to each household in the sample depending on which of the four groups it belonged to. For example, if $p_{11}$ was fixed at 0.65 , a value of $U=1$ with probability 0.65 was attributed to each household with a backup generator $(T=1)$ and which stated aboveaverage WTP $(Y=1)$. We then estimated the effect of having a generator on WTP, including $U$ as a further observed covariate. We repeated this matching process a large number of times for the given set of values of the sensitivity parameters $p_{11}-p_{00}$. We obtained an estimate of the effect of having a backup generator as the average of the estimated ATT effects over the distribution of the simulated $U$ s.

The estimated results from this process are reported in Table D.1. As previously stated, we fixed the probabilities $\operatorname{pr}(U=1)$ and the difference $d^{\prime}=p_{11}-p_{00}$ at pre-determined values. This was done to reduce

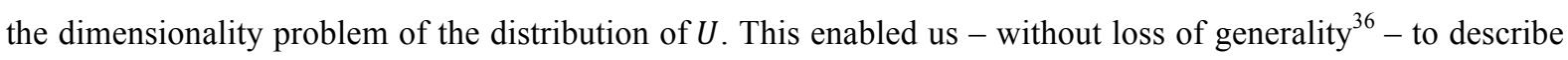
the simulated confounder fully by the difference $d=p_{01}-p_{00}$ and $s=p_{1 .}-p_{0 .}{ }^{37}$

\footnotetext{
${ }^{36}$ Since these terms are not expected to pose a real threat to the baseline estimate, they can be held constant and the simulated confounder $U$ can be fully described by the difference $d=p_{01}-p_{00}$ and $s=p_{1}-p_{0 .}$.

${ }^{37} \mathrm{We}$ only consider the positive values of $d$ and $s$. By setting $p_{01}>p_{00}$, one can simulate a confounding factor that has a positive effect on the untreated outcome. Similarly, by assuming $p_{1}>p_{0}$, one can simulate a confounding factor that has a positive effect on treatment assignment.
} 
Table D. 1 shows the estimated values of $\Lambda$ and $\Gamma$, where $\Lambda$ captures the effect of $U$ on the probability that a household uses a backup generator (the selection effect) and $\Gamma$ represents the effect of $U$ on WTP (the outcome effect). ${ }^{38}$ The key finding from the table is that even if the distribution of $U$ is characterised in such a way that it has a large effect on the probability that a household will use a backup generator $(\Lambda=7.01)$ and a large effect on WTP $(\Gamma=3.95)$, the estimate of the corresponding effect of using a generator on WTP remains positive. To reverse the estimate to have a negative effect of about $211, U$ needs to increase the relative probability of owning a generator $(\Lambda)$ by an implausibly large factor greater than 9.72 and the relative probability of stating above-mean WTP $(\Gamma)$ by an implausibly large factor greater than 11.20. Also, if $U$ is calibrated to the mimic variable 'home business ownership' dummy (a dummy indicating whether a household has a home business), we get a selection effect of $\Lambda=1.25$ and an outcome effect of $\Gamma=0.90$. This suggests that it is very unlikely that the finding that owning a backup generator tends to increase WTP is driven by some unobserved component.

Table D.1: Average treatment effects from the matching algorithm with an unobserved component

\begin{tabular}{l|lllll}
\hline & \multicolumn{3}{|c}{$s=0.3$} & \multicolumn{1}{c}{$s=0.5$} \\
& $s=0.1$ & $s=0.2$ & $\Lambda \in(3.61 ;$ & $s=0.4$ & $\Lambda \in(9.46 ;$ \\
& $\Lambda \in(1.47 ; 1.62)$ & $\Lambda \in(2.19 ; 2.58)$ & $5.14)$ & $\Lambda \in(5.77 ; 18.82)$ & 27.59 \\
\hline$d=0.1$ & 215.72 & 197.58 & 177.25 & 155.02 & 149.92 \\
$\Gamma \in(1.55 ; 1.66)$ & $(17.71)$ & $(27.10)$ & $(51.09)$ & $(63.09)$ & $(86.53)$ \\
$d=0.2$ & 204.53 & 176.22 & 134.22 & 104.20 & 67.36 \\
$\Gamma \in(2.35 ; 2.50)$ & $(21.39)$ & $(30.35)$ & $(41.74)$ & $(70.28)$ & $(90.17)$ \\
$d=0.3$ & 192.63 & 153.68 & 103.77 & 38.12 & -46.00 \\
$\Gamma \in(3.64 ; 4.41)$ & $(23.99)$ & $(35.12)$ & $(45.83)$ & $(63.26)$ & $(85.41)$ \\
$d=0.4$ & 176.53 & 121.52 & 50.18 & -31.25 & -144.96 \\
$\Gamma \in(6.97 ; 11.25)$ & $(26.79)$ & $(33.83)$ & $(46.27)$ & $(62.61)$ & $(76.81)$ \\
$d=0.5 \Gamma \in(16.58 ;$ & 162.19 & 93.61 & 2.40 & -96.37 & -262.98 \\
$129.03)$ & $(30.05)$ & $(38.05)$ & $(43.48)$ & $(54.70)$ & $(46.54)$ \\
\hline
\end{tabular}

Note: Standard errors in parentheses.

\section{REFERENCES}

Abdullah, Sabah, and P Wilner Jeanty. (2011). "Willingness to Pay for Renewable Energy: Evidence from a Contingent Valuation Survey in Kenya." Renewable and Sustainable Energy Reviews 15 (6): 2974-83.

Abdullah, Sabah, and Petr Mariel. (2010). "Choice Experiment Study on the Willingness to Pay to Improve Electricity Services.” Energy Policy 38 (8): 4570-81.

Adenikinju, Adeola F. (2003). "Electric Infrastructure Failures in Nigeria: A Survey-Based Analysis of the Costs and Adjustment Responses.” Energy Policy 31 (14): 1519-30.

Alberini, Anna, Marcella Veronesi, and Josph C Cooper. (2005). "Detecting Starting Point Bias in Dichotomous-Choice Contingent Valuation Surveys.” Nota Di La Voro 119. http://www.feem.it/userfiles/attach/20129181628434NDL2005-119.pdf.

An, Li, Frank Lupi, Jianguo Liu, Marc A Linderman, and Jinyan Huang. (2002). "Modeling the Choice to Switch from Fuelwood to Electricity Implications for Giant Panda Habitat Conservation.” Ecological

\footnotetext{
${ }^{38}$ Matching uses the kernel algorithm. Standard errors are computed using the between-imputation variance.
} 
Economics 42: 445-57.

Baker, T. L. (1994). Doing Social Research. 2nd ed. New York: McGraw-Hill Inc.

Bateman, Ian J, Diane Burgess, W. George Hutchinson, and David I Matthews. (2008). "Preference Learning versus Coherent Arbitrariness: NOAA Guidelines or a Learning Design Contingent Valuation (LDCV)." Journal of Environmental Economics and Management 55 (1): 1-25.

Beenstock, Michael, Ephraim Goldin, and Yoel Haitovsky. (1997). "The Cost of Power Outages in the Business and Public Sectors in Israel: Revealed Preference vs. Subjective Valuation.” Energy Journal 18 (2): 39 61.

(1998). "Response Bias in a Conjoint Analysis of Power Outages.” Energy Economics 20 (2): 135-56.

Bental, Benjamin, and S Abraham Ravid. (1982). "A Simple Method for Evaluating the Marginal Cost of Unsupplied Electricity." The Bell Journal of Economics 13 (1): 249-53.

Blumenschein, Karen, Magnus Johannesson, Glenn C Blomquist, Bengt Liljas, and Richard M O’Conor. (1998). "Experimental Results on Expressed Certainty and Hypothetical Bias in Contingent Valuation." Southern Economic Journal 65 (1): 169-77.

Blumenschein, Karen, Magnus Johannesson, Krista K Yokoyama, and Patricia R Freeman. (2001). "Hypothetical versus Real Willingness to Pay in the Health Care Sector: Results from a Field Experiment." Journal of Health Economics 20: 441-57.

Boyle, Kevin J. (2003). "Contingent Valuation in Practice." In A Primer on Non-Market Valuation, edited by Patricia A Champ, Kevin J Boyle, and Thomas C Brown, 111-69. London, Boston, Dordrecht: Kluwer Academic Publishers.

Carlsson, Fredrik, and Peter Martinsson. (2007). "Willingness to Pay among Swedish Households to Avoid Power Outages: A Random Parameter Tobit Model Approach.” The Energy Journal 28 (1): 75-89.

- (2008). "Does It Matter When a Power Outage Occurs? - A Choice Experiment Study on the Willingness to Pay to Avoid Power Outages.” Energy Economics 30 (3): 1232-45.

Carson, Richard T, and Theodore Groves. (2007). "Incentive and Informational Properties of Preference Questions.” Environmental and Resource Economics 37 (1): 181-210.

Caves, Douglas W, Joseph A Herriges, and Robert J Windle. (1992). "The Cost of Electric Power Interruptions in Industrial Sector: Estimates Derived from Interruptible Service Programs.” Land Economics 68 (1): 4961.

Caves, Douglas W., Joseph A. Herriges, and Robert j. Windle. (1990). “Customer Demand for Service Reliability in the Electric Power Industry: A Synthesis of the Outage Cost Literature.” Bulletin of Economic Research 42 (2): 79-119. doi:10.1111/j.1467-8586.1990.tb00294.x.

Eleri, Ewah Otu, Okechukwu Ugwu, and Precious Onuvae. (2012). "Expanding Access to Pro-Poor Energy Services in Nigeria.” International Centre for Energy, Environment \& Development, Nigeria.

Gunatilake, Herath, Narasimhamurty Maddipati, and Sumeet Patail. (2012). "Willingness to Pay for Good Quality, Uninterrupted Power Supply in Rural Madhya Pradesh, India.” ADB South Asia Working Paper Series No. 13. Mandaluyong City, Philippines.

Gunatilake, Herath, Sumeet Patail, and Jui Chen Yang. (2012). "Valuing Electricity Service Attributes: A Choice Experiment Study in Madhya Pradesh, India.” ADB Economics Working Paper Series 316. Mandaluyong City, Philippines.

Haab, Timothy C, and Kenneth E McConnell. (2002). Valuing Environmental and Natural Resources: The Economics of Non-Market Valuation. Northampton MA, US: Edward Elgar.

Halstead, John M, A E Luloff, and Thomas H Stevens. (1992). "Protest Bidders in Contingent Valuation." Northeastern Journal of Agricultural and Resource Economics 21 (2): 247-361.

Hanemann, Michael, John Loomis, and Barbara Kanninen. (1991). "Statistical Efficiency of Double-Bounded Dichotomous Choice Contingent Valuation.” American Journal of Agricultural Economics 73 (4): 125563.

Hanemann, Michael W, and Barbara Kanninen. (1998). "The Statistical Analysis of Discrete-Response CV Data.” Department of Agriculture and Resource Economics and Policy Working Paper 798. US: University of California at Berkeley. http://are.berkeley.edu/ gh082644/wp798.pdf.

Hartman, Raymond S, Michael J Doane, and Chi-Keung Woo. (1991). "Consumer Rationality and the Status 
Quo.” The Quarterly Journal of Economics 106 (1): 141-62.

Herriges, J.a., and J.F. Shogren. (1996). "Starting Point Bias in Dichotomous Choice Valuation with Follow-Up Questioning.” Journal of Environmental Economics and Management 30: 112-31.

Ichino, Andrea, Fabrizia Mealli, and Tommaso Nannicini. (2008). "From Temporary Help Jobs to Permanent Employment: What Can We Learn from Matching Estimators and Their Sensitivity?" Journal of Applied Econometrics 23: 305-27.

Layton, David F, and Klaus Moeltner. (2005). "The Cost of Power Outages to the Heterogenous Households: An Application of the Mixed Gamma-Lognormal Distribution." In Applications of Simulation Methods in Environmental and Resource Economics, edited by Anna Alberini and Ricardo Scarpa, 35-54. Kluwer Academic Press.

Longo, Alberto, David Hoyos, and Anil Markandya. (2015). "Sequence Effects in the Valuation of Multiple Environmental Programs Using the Contingent Valuation Method.” Land Economics 91 (1): 20-35.

Loomis, John, Thomas Brown, Beatrice Lucero, and George Peterson. (1996). "Improving Validity Experiments of Contingent Valuation Methods: Results of Efforts to Reduce the Disparity of Hypothetical and Actual Willingness to Pay." Land Economics 72 (4): 450-61.

Lopez-Feldman, Alejandro. (2012). "Introduction to Contingent Valuation Using Stata.” MPRA Paper 41018. http://mpra.ub.uni-muenchen.de/41018/.

Matsukawa, Isamu, and Yoshifumi Fujii. (1994). "Customer Preferences for Reliable Power Supply: Using Data on Actual Choices of Back-up Equipment." The Review of Economics and Statistics 76 (3): 434-46.

McGuirk, A. M, K Stephenson, and D. B Taylor. (1989). "The Use of Tobit Analysis in the Valuation of Nonmarket Resources.” Department of Agricultural Economics SP89-23. Blacksburg, VA: Virginia Polytechnic Institute and State University.

Mgbeokwere, Cynthia. (2013). "Generator Sales in Nigeria to Hit N151bn by 2020.” Nigerian Vanguard, April 5. http://www.vanguardngr.com/2013/04/generat or-sales-in-nigeria-to-hit-n151bn-by-2020/.

Mitchell, Robert C, and Richard T Carson. (1989). Using Surveys to Value Public Goods: The Contingent Valuation Method. Washington D.C.: Resources for the Future.

Munasinghe, Mohan. (1980). "Costs Incurred by Residential Electricity Consumers Due to Power Failures." Journal of Consumer Research 6 (4): 361-69.

National Bureau of Statistics (NBS). (2009). "Social Statistics in Nigeria, Federal Republic of Nigeria." Abuja, Nigeria.

. (2010). "Annual Abstract of Statistics, Federal Republic of Nigeria.” Abuja, Nigeria: National Bureau of Statistics.

. (2012a). "Basic Information Document: Nigeria General Household Survey - Panel, March 2012." Abuja, Nigeria: National Bureau of Statistics. http://www.nigerianstat.gov.ng/.

—. (2012b). "LSMS - Integrated Surveys on Agriculture: General Household Survey Panel 2010/11." Abuja, Nigeria: National Bureau of Statistics.

- (2012c). "Social Statistics in Nigeria: Part I - Household and Housing Condition.” Abuja, Nigeria: National Bureau of Statistics.

Newbery, David M. (2002). "Issues and Options for Restructuring Electricity Supply Industries.” Cambridge Working Papers in Economics 0210. Cambridge, UK: University of Cambridge.

Nnaji, Bart. (2010). "Strategy for Reform and the Enabling Environment. A Presentation Made at the 'Presidential Retreat for Power Sector Investors' State House, Abuja, 14-15th October 2010." http://www.accessbankplc.com/Library/Documents/2010 Bankers Committee Conference Resources/Power Sector/Power sector investors.pdf.

Nomura, Noboru, and Makoto Akai. (2004). "Willingness to Pay for Green Electricity in Japan as Estimated through Contingent Valuation Method." Applied Energy 78 (4): 453-63.

Ogundipe, Sola. (2013). “Portable Generators: Standby Power or Standby Death?” Nigerian Vanguard, October 9. http://www.vanguardngr.com/2013/10/portable-generators-standby-power-standby-death/.

Oseni, Musiliu O, and Michael G Pollitt. (2013). “The Economic Costs of Unsupplied Electricity: Evidence from Backup Generation among African Firms.” EPRG. University of Cambridge, Cambridge UK: EPRG Working Paper 1326. 
Otegbulu, Austin C. (2011). “A Contingent Valuation Model for Assessing Electricity Demand.” Journal of Financial Management of Property and Construction 16 (2): 126-46.

Ozbafli, Aygul, and Glenn P. Jenkins. (2016). "Estimating the Willingness to Pay for Reliable Electricity Supply: A Choice Experiment Study.” Energy Economics 56: 443-52. doi:10.1016/j.eneco.2016.03.025.

Presidential Task Force on Power. (2011). "POWER SECTOR OUTLOOK IN NIGERIA: Governments Renewed Priorities. A Presentation Made by Prof. Bart Nnaji, The Chairman, Presidential Task Force on Power, at Security and Exchange Commission, June 2011.” http://www.sec.gov.ng/files/Prof Nnaji Presentation.pdf.

. (2012). "Presentation by the Electricity Distribution Companies at the National Power Summit Uyo, 24-25 February." http://nigeriapowerreform.org/index.php?option=com_rokdownloads\&view=folder\&Itemid=169.

Roe, Brian, Mario F. Teisl, Alan Levy, and Matthew Russell. (2001). "US Consumers' Willingness to Pay for Green Electricity." Energy Policy 29 (11): 917-25.

Rosenbaum, Paul R, and Donald B Rubin. (1983). "The Central Role of the Propensity Score in Observational Studies for Causal Effects.” Biometrika 70 (1): 41-55.

Scarpa, R, and I Bateman. (2000). "Efficiency Gains Afforded by Improved Bid Design versus Follow-up Valuation Questions in Discrete-Choice CV Studies." Land Economics 76 (2): 299-311. doi: $10.2307 / 3147230$.

Thaler, Richard H. (1985). "Mental Accounting and Consumer Choice.” Marketing Science 4 (3): 199-214.

Townsend, Alan. (2000). “Energy Access, Energy Demand, and the Information Deficit.” In Energy Services for the World's Poor, 8-24. Washington DC: ESMAP.

http://www.worldbank.org/html/fpd/esmap/energy_report2000/ch2.pdf.

Tversky, Amos, and Daniel Kahneman. (1974). "Judgment under Uncertainty: Heuristics and Biases." Science 185 (4157): 1124-31.

Twerefou, Daniel Kwabena. (2014). "Willingness to Pay for Improved Electricity Supply in Ghana.” Modern Economy 5: 489-98.

United Nations Statistical Division. (2005). Designing Household Survey Samples: Practical Guidelines. Studies in. New York: Department of Economics and Social Affairs, United Nations Statistical Division. http://unstats.un.org/unsd/demographic/sources/surveys/Handbook23June05.pdf.

Veronesi, Marcella, Anna Alberini, and Joseph C. Cooper. (2011). "Implications of Bid Design and Willingness-To-Pay Distribution for Starting Point Bias in Double-Bounded Dichotomous Choice Contingent Valuation Surveys." Environmental and Resource Economics 49: 199-215.

Wacker, Garry, and Roy Billinton. (1989). “Customer Cost of Electric Service Interruptions.” In Proceeding of the IEEE, 77:919-30.

Weaver, Ray, and Shane Frederick. (2012). “A Reference Price Theory of the Endowment Effect.” Journal of Marketing Research 49 (5): 696-707.

Woo, Chi-Keung, and Roger L. Pupp. (1992). “Costs of Service Distruptions to Electricity Consumers.” Energy 17 (2): 109-26.

World Bank. (2003). "Making Services Work for Poor People. World Development Report 2004.” Choice Reviews Online. Vol. 41. Washington D.C. doi:10.5860/CHOICE.41-5366. 